\title{
Overconfidence and Uncertainty: High School Students' Beliefs About College Tuition and Their Subsequent College-Entry Rates
}

\author{
Stephen L. Morgan \\ Johns Hopkins University \\ Daniel T. Shackelford \\ Johns Hopkins University \\ Working Paper, Department of Sociology, Johns Hopkins University \\ August 17, 2018 \\ (Prior draft: April 11, 2017) \\ * Direct correspondence to Stephen L. Morgan (stephen.morgan@jhu.edu) at Department \\ of Soiology, 3400 N. Charles St., Johns Hopkins University, Baltimore, MD 21218 or Daniel T. \\ Shackelford (danielshackelford@jhu.edu) at School of Education, 2800 N. Charles St., Johns
} Hopkins University, Baltimore, MD 21218. 


\title{
Overconfidence and Uncertainty: High School Students' Beliefs About College Tuition and Their Subsequent College-Entry Rates
}

\begin{abstract}
Drawing on the decision-making literature that has considered mechanisms of overconfidence in judgment, this article offers an analysis of the base-year through 2016 followup waves of the High School Longitudinal Study of 2009 in order to address a core question in the study of educational attainment: How are high school students' beliefs about college tuition related to their subsequent postsecondary enrollment decisions? We find that ninth-grade students, on average, overestimate the tuition and mandatory fees for bachelor's degrees at public universities in their states of residence. In addition, the ninth-grade students who are most likely to enter college in the year after high-school graduation are (1) the students who are most likely to overestimate tuition and fees and (2) the students who are least confident in the accuracy of their estimates of tuition and fees. These results demonstrate how much additional work is needed to collect and analyze better forms of data that can enable deeper modeling of the forward-looking beliefs that are assumed to matter in most behavioral models of the social stratification process that incorporate educational attainment.
\end{abstract}




\section{Overconfidence and Uncertainty: High School Students' Beliefs About College Tuition and Their Subsequent College-Entry Rates}

The latest US Department of Education survey of high school students - the High School Longitudinal Survey of 2009, which samled ninth graders in 2009 and is expected to conclude with its final round of data collection in 2021 - was designed to enhance the modeling of postsecondary enrollment decisions, both to inform basic research on decision making and to shape policy debates on college access and affordability. In this article, we consider how students' beliefs about college tuition and mandatory fees are related to enrollment decisions following high school graduation.

Our measures of beliefs are based on a new set of questions that the National Center for Education Statistics has debuted in its high school longitudinal studies program. These questions include two primary questions that are the focus of our analysis:

- What is your best estimate of the cost of one year's tuition and mandatory fees at a public 4-year college in your state?

Include the cost of courses and required fees such as student activity fees and student health fees. Do not include optional expenses such as room and board.

- How confident are you in the accuracy of your estimate of the cost of one year's tuition and mandatory fees at a public 4-year college in your state? Are you ...

Very confident

Somewhat confident or

Not at all confident?

The first question follows from many past attempts to assess student knowledge and beliefs about the direct costs of a college education, which used to be defined as tuition alone but now also includes mandatory fees (see the clarification in the question above). The second question 
was introduced with unclear goals, but it is reasonable to assume that it was designed to reveal the uncertainty that students attach to their estimates of tuition and fees.

In the remainder of this introductory section, we first summarize the background scholarship on the relationships between students' beliefs and educational attainment. We then consider the specific literature on beliefs about the direct costs of college. Our goal is to motivate the subsequent empirical examination by demonstrating that the extant literature offers good reason to doubt simple expectations about the relationships among beliefs about tuition and fees, one's own confidence in those beliefs, and subsequent postsecondary enrollment patterns.

\section{Students' Beliefs and Educational Attainment}

Since the 1950s, sociologists have studied the consequences of high school students' own beliefs for their future educational trajectories, most commonly by modeling the relationship between aspirations developed during adolescence and subsequent educational attainment in early adulthood (e.g., Kahl 1953; Sewell, Haller, and Portes 1969; Spenner and Featherman 1978; Sewell, Hauser, Springer, and Hauser 2004). Over the same time period, economists have developed behavioral models for choices about postsecondary education that are also centered on beliefs - in this case, that prospective college students, when making forward-looking choices, develop and maintain reasonable beliefs about the costs and benefits of alternative courses of postsecondary training (e.g., Manski and Wise 1983; Manski 1989, 1993; Hoxby 2004).

The centrality of individual beliefs to these models of educational attainment, as well as concern about the validity of their inherent mechanisms, has led to additional work that seeks 
to better understand how students develop their plans during the transition to college (e.g., McDonough 1997; Schneider and Stevenson 1999; Bozick, Alexander, Entwisle, Dauber, and Kerr 2010; Grodsky and Riegle-Crumb 2010). Some of this newer work has also considered how occupational plans, and uncertainty therein, can enhance models that treat educational aspirations and expectations as the primary measures of students' own beliefs (see Morgan, Leenman, Todd, and Weeden 2013a, 2013b). Economists, relatedly, have deepened the evidentiary claim that high school students maintain reasonable beliefs about wage returns to investments in education (see Dominitz and Manski 1996; Rouse 2004), although without much direct examination of how uncertainty in these beliefs can be consequential for decisions. In dialogue with all of these arguments, some sociologists have developed theoretical and empirical work on how students make forward-looking choices, giving explicit attention to the consequences of uncertainty and heterogeneity in students' underlying beliefs about both the costs and long-term benefits of college degrees (e.g., Breen 1999; Morgan 2005; Jackson 2013).

\section{Students' Beliefs About Tuition and Fees}

In the past two decades, a focused literature on beliefs about college tuition and mandatory fees has also emerged. Although often framed by broad discussions of college access and affordability, this targeted literature is focused on two tractable questions that motivate empirical analysis:

1. Do students have accurate beliefs about the direct costs of a college education? 
2. Are students who overestimate the direct costs of college more likely to forego postsecondary training? ${ }^{1}$

To develop information to address these questions, researchers have considered national data sources with broad-gauge questions on beliefs about tuition, as well as small-scale studies that consider beliefs about tuition at local postsecondary gateway institutions. For the most heavily cited version of the former, Horn, Chen, and Chapman (2003) consider the tuition estimates of students and parents who responded to the 1999 National Household Education Survey. ${ }^{2}$ For an example of the latter, Avery and Kane (2004) consider two groups of high-performing students living in the Boston metropolitan area. One group was drawn from three high schools in the city served by a mentoring program, and for which the majority of students did not have a parent with any college education. The second group was drawn from a single affluent suburban high school without a mentoring program and where 92 percent of students had a parent with at least some college education. Both groups were asked to estimate tuition at Bunker Hill Community College and at the University of Massachusetts, Boston.

Although different in design, these two types of studies yield similar results. For national samples, students, on average, overestimate full-time tuition, typically by 100 percent

\footnotetext{
1 This literature, in many cases, is motivated by questions of clear importance that are pitched above the level of students' own beliefs: Are college costs so high that they are a barrier to entry among talented prospective college students who lack access to funds to meet the costs of college? Such questions have proven difficult to answer in ways that have generated a scholarly consensus, even though most sociologists of education accept that an affirmative answer to this particular question is self-evident. Nonetheless, we do not engage, in this article, in debates on whether college tuition is too high, whether financial aid is too limited to lower the net cost of attendance for low-income students, or whether procedural barriers in the college choice process need to be dismantled. We refer the reader to the vast literature that has directly engaged these questions, with exemplars such as Kane (1999), Dynarski (2003), Hoxby (2004), and Goldrick-Rab (2016). What we are most interested in, as this article will show, is developing the case for deeper and more systematic modeling of students' belief-based behavior, which will allow us to critically examine how students make choices. The lack of consensus in the literature on costs and college access suggests to us that we have much to learn about how students make choices, and hence that sustained attention to the "basic science" of how students make choices remains vital.

2 See also Grodsky and Jones (2007) for an extended analysis of the same parents of the sampled students.
} 
or more. Likewise, in Avery and Kane's study, the two groups of respondents reported average estimates of $\$ 11,525$ and $\$ 11,255$ for one year's tuition at UMass-Boston, while, at the time, the true tuition was only $\$ 4,681$. For Bunker Hill Community College, the two groups' average estimates were $\$ 5,941$ and $\$ 6,055$, but the true tuition was only $\$ 2,040 .^{3}$

Because most of these studies are cross-sectional, they do not provide direct evidence about whether those students most likely to overestimate tuition are disproportionately likely to forego college. Nearly all of these studies, however, suggest that overestimation is an indicator that students are likely to see the high listed price of college as discouragement, which is the position taken up in a widely-read policy document on improving college access by clarifying information and simplifying the application process for financial aid (ACSFA 2005).

\section{Confidence: Certainty or Overprecision?}

What about the second focal question we introduced above, where the student is asked to reveal their level of confidence - "very confident," "somewhat confident," or "not at all confident" - in the accuracy of their estimate of tuition and fees? For this question, a guiding prior empirical literature on confidence in the accuracy of tuition estimates are not available. Instead, alternative theoretical perspectives suggest completely divergent predictions.

Consider first the foundational model of rational choice under uncertainty, often labeled statistical decision theory, which would suggest that the students who are most confident in the

\footnotetext{
${ }^{3}$ Studies such as Horn et al. (2003) and Grodsky and Jones (2007) show that overestimation is somewhat lower for more general questions in national samples around the same time, although direct comparisons are impossible because of differences in handling those who decline to offer specific dollar-valued estimates. For an example of a related targeted study that also documents a tendency to overestimate, see Bettinger, Long, Oreopoulos, and Sanbonmatsu (2012). Oreopoulos and Dunn (2014) show that overestimation appears to be present in Canada as well.
} 
accuracy of their estimates of tuition and fees will be the students most likely to enter college. This prediction is based on two lines of reasoning.

First, students with access to abundant information on the true costs of a college education will have more certain and less variable beliefs about the "sticker prices" of tuition and fees, as well as supplementary beliefs about how much scholarship and financial aid programs can lower the actual costs that must be paid. When asked individually, these wellinformed students will express more confidence in the point estimates they offer for all types of costs, including for tuition and mandatory fees. When these students are considered as a group, in comparison to those who lack abundant information, they will have accurate and more narrowly varying point estimates of tuition and fees.

Second, because college is a risky choice with a large but variable payoff, students with more certain beliefs, measured by confidence in the accuracy of their own point estimates of all types of costs, will be more likely to enroll in postsecondary education, all else equal. These students know more about the costs of college and as a result can recognize that its benefits are obtainable because its costs are manageable. They commit to postsecondary education well in advance of enrollment decisions, making the necessary investments in their own college readiness.

For these predictions to hold for well-informed HSLS students, the level-of-confidence responses elicited by the second question above must be valid measures of the certainty of students' beliefs about tuition and fees. There are reasons to doubt this validity, as explained below. However, this basic perspective on information and uncertainty is not itself controversial, and we would argue that a weak form of it represents the conventional wisdom 
in policy work on higher education. Recommendations to lower college tuition and fees, while providing accurate information on costs and available aid, are commonly justified by some version of this behavioral model, even if the language of choice under uncertainty is not used explicitly (see ACSFA 2005). Even pieces that seek to differentiate their interpretive frame by invoking cultural and ecological perspectives often develop policy recommendations to provide accurate information on tuition and fees in order to reduce uncertainty and improve college access (e.g., Luna De La Rosa 2006; Perna 2006; Tierney and Venagas 2009).

Although the choice perspective on the consequences of certainty, measured by confidence, lines up with conventional wisdom, an alternative perspective suggests a sharply contrasting prediction: that confidence in one's estimate of tuition and fees will predict lower levels of postsecondary enrollment. This alternative prediction is shaped by a newer literature on "overconfidence," and especially its embedded stream of literature on "overprecision." This literature is found within the interdisciplinary social science community that conducts research on judgment and decision making (see Block and Harper 1991; Soll and Klayman 2004; Moore and Healy 2008; Moore, Carter, Yang 2015). ${ }^{4}$ For the overprecision literature, experimental subjects are asked for numerical answers to specific questions, often forecasts of their own performance on a future task. After supplying an estimate, they are then asked to provide plausible intervals for their estimates and/or about their overall confidence in their initial numerical answers. Subjects consistently select ranges that are too narrow relative to objective performance and/or express more confidence in their estimates than is warranted. In behavioral

\footnotetext{
4 The literature on overconfidence is notable for the competing definitions of its basic concepts and effects. For a review and an attempt at clarity, see Moore, Tenney, and Haran (2015).
} 
economics, where overprecision is often labeled "miscalibration," these effects are thought to be widespread (see Daniel and Hirshleifer 2015; Grubb 2015). ${ }^{5}$

If overprecision and miscalibration are common, why then would heightened confidence in one's estimate of tuition and fees predict lower levels of postsecondary enrollment? The literature suggests two mechanisms: (1) overconfidence is a signal of a deficit of higher-level cognitive skills and (2) overconfidence increases the reluctance to revise one's beliefs.

For the first mechanism, a series of psychology experiments suggests that individuals who are overprecise also lack the "metacognition" that would allow them to recognize their overprecision. As Kruger and Dunning (1999:1121) write, "the skills that engender competence in a particular domain are often the very same skills necessary to evaluate competence in that domain - one's own or anyone else's." ${ }^{\prime}$ How far these domain effects spread beyond the immediate task at hand is not clear from this experimental literature, although some assessments suggest substantial spillover (see Ben-David et al. 2013). Applied to the context considered in this study, this mechanism suggests that a disproportionate share of individuals who express substantial confidence in their tuition estimates could also be signaling on the survey instrument that they are in fact poor performers in general, lacking skills in the higherlevel thinking that is related to both survey-based estimation exercises and everyday

\footnotetext{
${ }^{5}$ As Ben-David, Graham, and Harvey (2013:1549) write, "Miscalibrated people overestimate the precision of their own forecasts or underestimate the variance of risky processes; in other words, their subjective probability distributions are too narrow. We use the terms miscalibration and overprecision interchangeably."

${ }^{6}$ This effect is described in other ways as well, especially in behavioral economics where the language of calibration is used. For example, Duttle (2016:S53) concludes from his work that "Interval forecasts of cognitively more able subjects were much better calibrated than those of their peers who displayed substantial overconfidence in the precision of their forecasts."
} 
schoolwork. If the poor performance of such students predisposes them to forego college, or renders them unprepared for college, then confidence in one's estimate of tuition and fees may be a valid indicator of a lack of preparation for college, either at the time the confidence judgment is offered or as will be developed in subsequent years.

For the second mechanism, students who are overconfident in their tuition estimates are more likely to ignore subsequent information that college is more affordable than they recognize at the time. ${ }^{7}$ These students may come to believe that they cannot afford postsecondary education and subsequently not attend, while students who are "not at all confident" in their estimates may be more likely to revise their estimates of tuition and fees downward in response to new information that college is affordable, or in response to influence from significant others such as parents and teachers.

Altogether, it is unclear what associations to expect between confidence in one's estimates and subsequent patterns of postsecondary education. For this reason, a descriptive empirical analysis seems particularly worthwhile, especially given the divergent implications for the future measurement of beliefs that would follow from either positive or negative associations. In the next section, we introduce the data source and lay out the design of our subsequent empirical analysis.

\section{DESIGN}

We analyze 2009 through 2016 panel data drawn from the HSLS. Still ongoing, the HSLS is a nationally representative sample of ninth graders who were enrolled in public and private high

\footnotetext{
${ }^{7}$ For the basic argument, although in different contexts, see Sieck and Arkes (2005), Yaniv (2004), and Grubb (2015).
} 
schools in the fall of 2009. To this data, we match information on in-state tuition and

mandatory fees at the time of the survey, gathered by the College Board through its Annual

Survey of Colleges. ${ }^{8}$ We describe the basic contours of the data we analyze in this section.

Additional detail is provided in the online Appendices A and B.

\section{Measures of Primary Interest}

We analyze responses to the two questions introduced above, which ninth graders were offered during the administration of the base-year HSLS survey. We model these responses as outcomes to be analyzed on their own and as predictors of college entry. For postsecondary enrollment, we model the probability of entering one of two states, "enrolled in a four-year college" and "enrolled in another type of postsecondary institution," in comparison to the baseline state of "not enrolled in any form of postsecondary education." This outcome is determined by an ensemble of indicators developed for a composite variable constructed by contractors to the US Department of Education, updated with the latest information in the 2016 wave. Finally, as described in detail in Appendix A, our five measures of SES use information from both the base year and the first follow-up surveys (in order to mitigate the consequences of missing parent data for the base year in combination with the decision not to ask back-up questions to students themselves in the base year). Additional measures utilized in our analysis will be explained as they are introduced into the results, and the means and standard deviations

8 See The College Board's 2016 Trends In College Pricing (https://trends.collegeboard.org/college-pricing). We used 2009-10 current dollar values, from Table 5, for public four-year college, in-state tuition and fees. These values are state averages, weighted by enrollment at each public four-year college within each state. 
of all adjustment variables used in subsequent models are reported in Appendix A (see Table A1).

\section{Analytic Sample}

Although we utilize a full 2009-2014 panel sample of 16,044 HSLS students (supplemented by 2016-updated measures when available), our most targeted analysis will be based on a nonrandom subsample of 9,004 students. These students (1) graduated from high school on time, (2) indicated in the ninth grade that they planned to obtain some type of postsecondary training in their first year after high school graduation, and (3) were asked the question in the ninth grade "What is your best estimate of the cost of one year's tuition and mandatory fees at a public 4-year college in your state?" The second and third conditions are necessary because of the complex skip patterns of the base-year student questionnaire.

Appendix B offers a full explanation of these skip patterns, including a reproduction of the base-year student questionnaire. In this section, we detail the three exclusion decisions that resulted in a primary analytic sample of 9,004 respondents:

1. Of the 16,044 panel respondents, we first excluded 1,623 students who did not graduate with a high school diploma on time. When weighted, the remaining 14,421 students represent 87.6 percent of the panel sample.

2. Of the 14,421 on-time high school graduates, we then excluded 4,254 students who did not indicate in the fall of the ninth grade that they planned to obtain some type of postsecondary training in their first year after high school graduation. When weighted, the remaining 10,167 students represent 59.7 percent of the panel sample. ${ }^{9}$

3. Of the 10,167 students who were both on-time high school graduates and began high school planning to obtain some type of postsecondary training in their first year after

\footnotetext{
${ }_{9}$ The group is composed of 8,294 respondents who planned to "enroll in a Bachelor's degree program in a college or university," 1,308 who planned to "enroll in an Associate's degree program in a two-year community college or technical institute," and 565 who planned to either "obtain a license or certificate in a career field" or "attend a registered apprenticeship program."
} 
high school graduation, we excluded 1,163 respondents who, as of the fall of their first-year of high school, had "gotten information about the costs of tuition and mandatory fees" for a specific four-year college that was consistent with their preferences for type of institution. ${ }^{10}$

If this third exclusion decision seems odd to the reader, we agree with that assessment. It is a feature of the HSLS design, which appears to have been structured to allow analysts to consider the beliefs about college tuition and fees of high school students who were (a) likely to consider attending any of the four-year public colleges in their own state, which is frequently the subset of high school students of most important policy concern, but (b) uncertain enough of their possible destinations that they had not received information about college costs at a specific four-year college by the fall of the ninth the grade. Fortunately, as we show at the beginning of our results section below, the number of students who reported that they had "gotten information" on costs for a specific four-year college by the fall the ninth grade is relatively small and only weakly patterned by many of the usual predictors of college entry.

\section{RESULTS}

In this section, we first present characteristics of the full panel sample in order to document the subsequent filtering of our primary analytic sample. We then analyze the distributions of students' beliefs about tuition and fees, and how these distributions vary with confidence.

\footnotetext{
10 Three types of respondents were excluded in this final filter: the 460 students who had gotten information on tuition for a specific four-year private college, 274 who had gotten information on tuition for a specific out-of-state, four-year public college, and 429 who had gotten information on tuition for a specific in-state, four-year public college. The 429 students who indicated that they planned to attend a specific four-year, in-state college were not asked the two focal questions introduced above, as explained carefully in Appendix B. Instead, they were asked for an estimate of the tuition and fees at that particular college, not about a non-specific college in the state (i.e., "a public 4-year college"). Equally consequential for our analysis, they were not then asked about their confidence in their estimate. When we recognized that we would not be able to include this group in our full analysis, we decided also to exclude students who had "gotten information" about any specific four-year college.
} 
Thereafter, we consider whether beliefs predict postsecondary attendance and, if so, in what configuration.

\section{Reported Information and Willingness to Offer an Estimate of Tuition and Fees}

Table 1 presents results for the full sample of HSLS students and as the sample is progressively filtered to our primary analytic sample of 9,044 respondents. Column 1 reports the percentages of ninth graders who subsequently graduated from high school on time by self-identified raceethnicity, gender, parents' education, family income, and a standardized math test score from the ninth grade. These variables are representative of the adjustment variables we will utilize in our models below (see Table A1 in Appendix A for a full list). Column 2 reports the percentages of students, broken down in the same fashion, who graduated high school on time and who also indicated in the ninth grade that they planned to obtain some type of postsecondary training in the first year after high school graduation.

\section{[ INSERT TABLE 1 ABOUT HERE ]}

The final row of Table 1 presents unconditional percentages for the full sample. As shown there, 87.6 percent of ninth graders graduated high school on time, but only 59.7 percent graduated high school on time after having indicated in the ninth grade that they planned to enroll in some type of postsecondary training in the year after high school graduation.

Examining the cross-sectional variation, the distributions in columns 1 and 2 are consistent with the literature. White and Asian students, female students, and students with advantaged family background measured by parents' education are more likely to be on trajectories toward higher 
levels of educational attainment. In addition, math test scores are strongly predictive, implying that academic preparation is consistent with the variation in these expected trajectories.

We next consider the remaining filtering of our analytic sample, which we explained in the last section is mostly determined by the skip patterns on the survey instrument (see also Appendix B for a detailed presentation of the skip patterns). For the results reported in columns 3 and 4 of Table 1, we first limit the sample to the 10,167 HSLS students who graduated high school on time and planned to attend postsecondary education (i.e., as identified by the percentage calculation for column 2). Across the same predictive dimensions, column 3 presents the percentage of these ninth graders who reported that they had "gotten information about the cost of tuition and fees" at a specific four-year college that was consistent with their preferences for type of postsecondary education. Only 10.6 percent of students reported that they had gotten such information. And, unlike for columns 1 and 2, raceethnicity, gender, parents' education, family income, and the math test score do not substantially predict which students claimed to have gotten this particular information. Differences are present, and in many cases in the expected directions, but the differences are small in comparison to those revealed in columns 1 and 2.

Column 4 then presents the percentages of students who were not among those who had gotten the specific information and who were also willing to offer a numerical estimate for tuition and mandatory fees at an in-state four-year college (e.g., the first focal question we have discussed extensively above). As shown in the last column, 78.8 percent of these students were willing to offer a specific numerical estimate. Similar to the results reported in column 3 , the variables for race-ethnicity, parents' education, and family income do not substantially predict 
willingness to offer an estimate. However, the math test score does weakly predict willingness to offer an estimate - by 5.5 percent from the $1^{\text {st }}$ to $4^{\text {th }}$ quartiles. In addition, there is a gender difference of 5.9 percent, with male ninth graders more likely to offer an estimate. Overall, the level of fluctuation in the rows of columns 3 and 4 is consistent with only a weak patterning.

Table 1 suggests a first important set of conclusions. As with all national data sources, race-ethnicity, gender, family background, and standardized test scores predict expected educational trajectories. However, within the subset of youth on the expected trajectory to some form of postsecondary education just after high school graduation, which for the HSLS is 59.7 percent of ninth graders, these factors only weakly predict self-reports of whether ninth graders had "gotten information" on costs for a specific four-year college. Therefore, we conclude, with some confidence, ${ }^{11}$ that the prospects for an effective analysis of students' beliefs about tuition and fees are not undermined by how the HSLS survey instrument constrains the definition of our analytic sample. The 9,004 students in our analytic sample have distributions of demographic and background characteristics that are similar to all 10,167 college-bound students in the HSLS. Indeed, one might argue that the analytic sample that the HSLS generates is at the "margin" of interest for explanatory theory with policy relevance: ninth graders predisposed to enroll in college after graduating high school, excluding the 10.6 percent who claimed to have gotten information on the costs of a specific four-year college that they already planned to attend.

\footnotetext{
${ }_{11}$ Although we do not claim to be immune to overprecision or miscalibration (see the introduction), we do feel that our metacognitive capacities are solid.
} 
Furthermore, Table 1 shows that, for our analytic sample, the willingness to offer a numerical estimate of tuition and fees is also only weakly patterned by standard predictors of educational attainment. Accordingly, when analyzing patterns of postsecondary enrollment below, we first offer a complete analysis of the students who provided an estimate, which is 79 percent of the analytic sample. We then incorporate the remaining 21 percent of the analytic sample and show that the overall conclusions change little because these two groups of students are sufficiently similar on measured characteristics that we know from a large body of preexisting research predict educational attainment.

\section{Student Estimates of Tuition and Fees}

Table 2 presents percentiles of students' estimates of tuition and fees, in response to the first focal question introduced above: “What is your best estimate of the cost of one year's tuition and mandatory fees at a public 4-year college in your state?" Numerical values are provided by 7,035 respondents, which is a weighted 78.8 percent of our primary analytic sample of 9,004 (the same group identified by the percentage calculation in column 4 of Table 1). The first row of Table 2 reports the $10^{\text {th }}, 25^{\text {th }}, 50^{\text {th }}, 75^{\text {th }}$, and $90^{\text {th }}$ percentiles of estimated tuition and fees for this group. The fifth row reports analogous percentiles after deviating students' estimates from the true average of the tuition and fees for the state in which they lived when they were sampled. The values are current-dollar amounts, as reported in fall of 2009. As shown in these two rows, the median estimate was $\$ 15,000$, and this value is $\$ 7,357$ larger than the true average for each student's state. The interquartile range of the estimates is $\$ 5,000$ to $\$ 30,000$. The value at the 
$25^{\text {th }}$ percentile is an underestimate of $\$ 1,734$ dollars, and the value at the $75^{\text {th }}$ percentile is an overestimate of $\$ 22,672$.

\section{[ INSERT TABLE 2 ABOUT HERE ]}

Table 2 also reports the distribution of estimates, conditional on confidence levels that were elicited by the second focal question discussed at length above. The (unweighted) numbers of respondents reported in the table indicate that the modal response to the confidence question was "somewhat confident." More students were "not at all confident" than were "very confident." Is confidence related to the size of the students' estimates? Rows 2 through 4 and 6 through 8 suggest no more than a very weak relationship, with no clear monotonic patterns, and with similar medians and interquartile ranges. Even the $10^{\text {th }}$ and $90^{\text {th }}$ percentiles are similar across the three groups.

What can we conclude about these distributions? Given past research, it is unsurprising that the HSLS students overestimated the tuition and mandatory fees of four-year colleges in their states. No definitive explanation has ever been offered to explain why this is typically the case. Candidate explanations include generalized pessimism about the opportunity structure and its constraints as well as students' inability to separate out estimates of tuition and fees from gross costs that include living expenses, even though the survey questions strongly push students to do so (see the prompts and clarification on page 1 and in the survey instrument in Appendix B). In this case, given that estimates were elicited in the fall after a recession had begun, which entailed tuition increases in many states to counterbalance declining state revenue, ninth graders may also have been particularly pessimistic (and/or forward-looking). 
What we do not have evidence for in Table 2 is that confidence is related to estimates of tuition and fees in any substantial way. Whether this finding is surprising to the reader, we cannot say, but it was surprising to us. At most, we might conclude, if examining only the $10^{\text {th }}$ percentile, $25^{\text {th }}$ percentile, and the median that the "very confident" group has slightly less pessimistic estimates at the median but more overly optimistic estimates in the left tail of the distribution. The general pattern, we think, is a great deal of similarity in the distributions of estimates when broken down by confidence.

Nonetheless, we should be cautious about over-interpreting what is possible when students are only asked to give a single point estimate of tuition and fees. It is possible, for example, that students who reported "not at all confident" might have also been willing to offer a range of plausible estimates that is wider than those who reported that they were "somewhat confident" or "very confident." We simply cannot assess this possibility with these data. Our overall conclusion, therefore, is that these three groups do not, collectively, seem to differ much in their beliefs about tuition and fees.

Regardless of one's reaction to the similarity of the distributions across the rows in Table 2, immediate questions for analysis arise. Does the level of the estimate, possibly when adjusted by true levels of tuition and fees, have a relationship with subsequent enrollment? Does confidence in one's estimate have any relationship with subsequent enrollment? We turn to these two questions in the next section. We conclude this section with brief reporting of supplementary models that consider how students' estimates and their confidence in them are both related to the demographic and background characteristics of students. 
As shown in Appendix A (see Table A2), estimates of tuition and fees are positively associated with measures of family background, such as family income, and with measures of academic performance, such as test scores and self-reported grades. These associations, while not strong, do line up with the claim in the literature that students from disadvantaged origins do not typically believe that tuition and fees are higher than other types of students. Instead, for example, HSLS students with higher levels of family income believe that tuition and fees are higher. Relatedly, students enrolled in private schools and in both suburban and rural schools have slightly higher estimates of tuition and fees than other students.

These associations line up to some extent with state-level variation. Figure 1 presents mean estimates for the HSLS students analyzed for Table 2, when collapsed to the state level and plotted against true average tuition and fees by state. The size of the circle for each state is scaled by the size of the within-state sample, and the state-level regression line in red is weighted by the size of each within-state sample. ${ }^{12}$ Because the HSLS sample is not necessarily representative of each state, based on the HSLS sampling design, one should not invest too much energy into interpreting the specific contours of the figure, or the sizes of the circles. What it shows is that HSLS students in states with higher tuition and fees on average provide estimates of tuition and fees that are higher. Higher-tuition states frequently also have higher levels of family income and parental education, and this is part of the underlying pattern revealed in Table A2.

\section{[ INSERT FIGURE 1 ABOUT HERE ]}

\footnotetext{
12 The sizes of the state samples do not align with the state population sizes because ten states were oversampled. The reader should not assume that the large circles are the largest states by population.
} 
We also show in Appendix A (see Table A3) that confidence can be predicted by students' characteristics. Average probability differences from ordered logit models with a rich set of adjustment variables reveal that an additional 9.1 percent of female students report that that they are "not at all confident" in their estimates of tuition and fees. Other smaller associations are present as well. Students who self-identify as Black or African-American are 7.9 percent less likely to offer "not at all confident," net of other adjustments for family background, school type, and academic performance. ${ }^{13}$ These gender and race differences are substantial, but we cannot say whether most readers would regard swings of 8 or 9 percent across these types of categories to be especially important. Interpretations may well depend on whether confidence itself is predictive, and we offer such models next.

\section{Postsecondary Enrollment Patterns, As Predicted by Students' Beliefs}

Table 3 presents three multinomial logit models, where the outcome is a three-category variable for postsecondary enrollment in the fall after on-time high school graduation. The reference enrollment state is "no postsecondary enrollment," and the two predicted enrollment states are enrollment in a four-year, bachelor's degree granting institution or enrollment in any other type of postsecondary institution. ${ }^{14}$ For now, we place no causal structure on these models and interpret them only in descriptive fashion (but see our discussion section below).

\footnotetext{
${ }^{13}$ Net of these groups differences, family background is only a minor factor. For example, a two-standard-deviation increase in (logged) family income is associated with a 3.7 percent increase in the probability of responding "not all confident." Other net associations with family background are even weaker.

${ }^{14}$ For Table 3, we offer models estimated for the 6,947 respondents for whom we have numerical values for estimates of tuition and fees, reports of confidence, and non-missing postsecondary enrollment (all but 1.2 percent of the students analyzed for Table 2). In Appendix A (see Table A4), we present patterns of enrollment for other members of the HSLS panel sample, as analyzed for Table 1. As shown there, 48.2 percent of our analytic sample enrolled in a four-year college, and another 26.0 percent enrolled in another type of institution. The corresponding enrollment
} 
For Model 1, we predict enrollment only from a single variable, the natural logarithm of the student's estimate of tuition and fees. For Model 2, we predict enrollment only from two indicator variables for level of confidence. For Model 3, we predict enrollment from the variables in both Models 1 and 2, along with the natural logarithm of the average true in-state tuition and fees at four-year colleges in the student's state of residence at the time the student's estimate was elicited.

\section{[ INSERT TABLE 3 ABOUT HERE ]}

Before interpreting the direction and size of the coefficients of each model, consider the basic patterns in a comparison of Models 1 and 2 to the combined Model 3. The values for the coefficients are very similar, and the main reason for this correspondence was already demonstrated above in Table 2. Variation in the size of the estimate of tuition and fees has little or no relationship to variation in confidence. As a result, when the three regressors in Models 1 and 2 are specified together, they have nearly the same associations with enrollment as when they are specified in separate models. Model 3 also shows, furthermore, that, when adjusting for true levels of the tuition and fees of the institutions about which the cost estimates are sought, these same relationships also appear unchanged.

Because logit coefficients are identified only up to scale, comparisons of these specific coefficients across Models 1 through 3 is inadvisable without scale adjustments. For this reason, we will offer average-probability-difference interpretations below that are scale invariant. Nonetheless, the directions of the coefficients are interpretable in these models, and they

numbers for those who had gotten information on costs at a specific four-year college by the ninth grade were 59.0 and 21.6 percent. 
suggest several important patterns already. First, the coefficient for the (natural logarithm) of estimates of tuition and fees indicates that higher estimates predict higher rates of four-year college entry (and to a lesser extent, entry into other types of postsecondary education as well). Second, confidence has a negative relationship with subsequent enrollment. In comparison to ninth graders who report "not at all confident," ninth graders who reported higher levels of confidence in their estimates were less likely to attend four-year colleges (and again, to a lesser extent, enter into other types of postsecondary education). Finally, the directions of these associations do not depend on whether we adjust for the true levels of tuition and fees.

Are these associations substantively large? The first two panels of Table 4 present average probability differences for the associations that both estimates of tuition and fees and confidence have with postsecondary enrollment, as reported respectively in Models 1 and 2 in Table 3. The third panel presents the analogous average probability differences estimated jointly by Model 3, which also includes an adjustment for true levels of tuition and fees. The average probability differences across these first three panels are very similar, indicating that no scaling complications afflict basic comparisons of coefficients across Models 1 through 3 in Table 3. We therefore consider Model 3 as our baseline model, and we offer substantive interpretations of it, instead of Model 1 or Model 2.

\section{[ INSERT TABLE 4 ABOUT HERE ]}

For estimates of tuition and fees, the coefficients in Model 3, 0.275 and 0.068, correspond to probability of enrollment differences of 0.058 and -0.021 (with standard errors of 0.007 and 0.005) for each unit on the log scale. Consider a natural log difference of 1.792 , which corresponds to the natural log difference for the interquartile range of students' estimates (e.g., 
$\$ 5,000$ to $\$ 30,000$ in the first row of Table 2). With this number, we can infer that an increase in an estimate from the $25^{\text {th }}$ to the $75^{\text {th }}$ percentile is associated with an increase in the four-year college enrollment rate of 10.4 percent (e.g., $1.792 \times 0.058 \times 100)$. The same increase is associated with a decrease in the enrollment rate of 3.8 percent at other types of postsecondary institutions (e.g., $1.792 \times-0.021 \times 100)$ and a decrease in the "no enrollment" rate of 6.6 percent of students (e.g., $1.792 \times-0.037 \times 100) .{ }^{15}$ By our reading of the literature, enrollment shifts of this magnitude would be considered moderately large, since shifts in response to financial aid interventions of only a few percentage points are often interpreted as effective.

The corresponding average probability differences for confidence indicate similarly substantial associations. As shown in the third panel of Table 4, the students with the most confidence in their estimates had a four-year college enrollment rate 18.8 percent lower than the least confident group of students, based on the probability difference of -0.188 for the comparison of "very confident" to "not at all confident." The middle group of somewhat confident students was in the middle on enrollment as well, with a four-year college enrollment rate that was 7.1 percent lower than the least confident group, based on the probability difference of -0.071 for the comparison of "somewhat confident" to "not at all confident." In the literature on college enrollment rates, and interventions designed to change them, enrollment rate changes of 18.8 percent would be considered large and changes of 7.1 percent would be considered moderately large. The remaining columns for Model 3 in Table 4 reveal, subject to the distributional assumptions of the multinomial logit model, how these shifts of 18.8 and 7.1

\footnotetext{
15 The multinomial logit model constrains these estimated shifts so that the increase of 10.4 is equal to a decrease of $3.8+6.6$.
} 
percent are divided across the other two outcomes. Most of the change (11.6 of 18.8 and 6.1 of 7.1) appears as a relative increase in the probability of not enrolling in any postsecondary education, and this is consistent with the pattern for tuition estimates as well (and is indicated by the relative sizes of the coefficient estimates in Model 3, scaling issues held aside).

Recall, again, that the associations for Model 3 are present even though we have adjusted for the true levels of tuition and fees in each student's own state at the time the students' estimate and level of confidence in it were elicited. As shown in Table 3, the coefficients for the natural logarithm of these true levels of tuition and fees are in the same direction for college enrollment. Two clarifications should be offered. This variable is an imperfect proxy for the true tuition and fees of public four-year colleges that students considered at the time of high school graduation (because tuition increased by different amounts across states in subsequent years, and because students did not necessarily live in the same state at the time of high school graduation in the summer of 2013 as they did when sampled in the fall of 2009). Nonetheless, by specifying this variable in Model 3, we can adjust to some degree for the tendency of students in higher tuition states to enter colleges at higher rates, which is a pattern sometimes attributed to average differences in family income across states. Therefore, we believe, based on Models 1 through 3, that the substantial associations that both estimates of tuition and fees and confidence have with actual enrollment is mostly independent of the associations that true tuition and fees have with enrollment.

The next obvious task for analysis is to consider how these associations change as we adjust for student and family characteristics. Table 4 includes estimates of average probability differences from three additional multinomial logit models, the coefficients of which are 
provided in Appendix A (see Table A5). ${ }^{16}$ For Model 4, we add to our baseline Model 3

adjustment variables for race-ethnicity, gender, family background, urbanicity, region, and type of school. For this model, the average probability differences that correspond to estimates of tuition and fees and levels of confidence decrease substantially in comparison to those of Model 3. For example, the average probability difference associated with the estimates of tuition and fees decreases from 0.058 to 0.034 (with a standard error of 0.006 ) for four-year college enrollment. And, for confidence, the probability differences of -0.188 and -0.071 decrease to 0.106 and -0.022 percent, respectively, for four-year college enrollment. Next, for Model 5, we instead adjust for math test scores in the ninth grade and self-reported math and science grades from middle school. This adjustment reduces the average probability differences even more (i.e., for four-year college enrollment, from 0.058 to 0.025 for estimates of tuition and fees and from of -0.188 and -0.071 to -0.046 and -0.020 , respectively, for confidence). Finally, for Model 6, we combine the adjustment variables from Models 4 and 5. For this model, the average probability differences are reduced to levels that are consistent with sampling error alone.

How should we interpret the consequences of these adjustments? In many ways, these adjustments are sensible and produce results that conform to our expectations. For example, we noted earlier that female students had less confidence in their estimates than male students. Because the recent literature shows that female students in this generation are more likely than male students to enter postsecondary education, it is not surprising that an adjustment for gender contributes to a reduction in the association between confidence and postsecondary

\footnotetext{
${ }^{16}$ Each of the included sets of adjustment variables greatly improves the prediction of postsecondary education, as revealed in Table 4 by the increases in the chi-square values that correspond to each model (which can be directly compared to the chi-square values for Model 3, which is nested in Models 4 through 6).
} 
enrollment. Similarly, as we also noted above, students with higher test scores and selfreported grades had lower average levels of confidence in their estimates. Because these students are more likely to enter postsecondary education, it is unsurprising that Model 5 in Table 4 shows that test scores and grades are effective at reducing the associations between confidence and enrollment outcomes.

Nonetheless, we lack foundational knowledge that allows us to place confidence in estimates of tuition and fees within a structural model that can warrant specific causal inferences, and thus we would be uncomfortable asserting that the small average probability differences for Model 6 in Table 4 support the position that students' beliefs about college tuition and fees do not have causal effects on postsecondary enrollment patterns. It is likely that many of these adjustment variables have effects that can be interpreted as endogenous with respect to beliefs about tuition and fees. We discuss these interpretive complications, and their implications for future research, in detail in the discussion section below.

Before concluding the presentation of our results, we offer one important final set of models. Table 5 presents average probability differences for five additional models analogous to Models 2-6 just presented in Table 4. ${ }^{17}$ These new models include additional students (comprising 21 percent of our analytic sample) who declined to offer numerical estimates and/or assess their confidence in their estimates. ${ }^{18}$ Accordingly, for these models, we expand the sample from these 6,947 to 8,939 students and, by necessity, replace the variable for the

\footnotetext{
${ }^{17}$ For the corresponding coefficients, see Appendix A, Table A6.

${ }_{18}^{18}$ Most of these students did not provide a cost estimate and thus were not asked the confidence question. Only 37 students provided a cost estimate but did not respond to the confidence question. We combine both groups for the model.
} 
specific numerical estimate with a dummy regressor variable for the additional students. This group of additional students is not easy to characterize, and we assume that it includes (at least) two types of students: (1) those students who declined to offer an estimate because they felt the question was burdensome and (2) those students who declined to offer an estimate because they felt that they lacked sufficient information to offer one. The latter group may be interpretable post hoc as lacking confidence in their ability to offer a numerical estimate, but based on what we have shown already about the HSLS confidence measure, we caution against this seemingly reasonable interpretation.

\section{[ INSERT TABLE 5 ABOUT HERE ]}

Notice that, although Models 2A through 6A in Table 5 have the same basic structure as Models 2 through 6 in Table 4, these new models do not include a variable for the estimate of tuition and fees; it is unavailable for the full estimation sample. Fortunately, we know from the results discussed already for Tables 3 and 4 that the omission of this variable is unlikely to affect the associations between confidence and postsecondary enrollment for those students who have measures of both (see, in particular, the similarity of Models 1 through 3 in Tables 3 and 4 above). The added students in Models 2A through 6A are parameterized by a new dummy regressor, which we label "No measure of confidence" (and, for nearly all of these students, we also do not have a measure for their estimate of tuition and fees; see last footnote).

For Model 2A, the average probability differences for "very confident" students and "somewhat confident" students are identical to the values for Model 2 in Table 4. The reason is simple: the comparisons that they capture are unaltered by the additional students incorporated for Model 2A. The new average probability difference for "No measure of 
confidence vs. Not at all" is equal to -0.114 for four-year college enrollment, 0.045 for other postsecondary enrollment, and 0.068 for no enrollment. These coefficients suggest that the students who do not offer estimates and confidence judgments, on average, have a four-year college entry rate that is 11.4 percent below those with no confidence in the estimates that they offer, with corresponding probability differences for the other enrollment states. Substantively, these students have an enrollment profile that is in between the "very confident" and "somewhat confident" group, which is what one would expect based on column 4 of Table 1, where we showed that the willingness to provide an estimate of tuition and fees and a confidence judgment is only weakly patterned by standard predictors of educational attainment. One might argue that this group of students is less likely than the whole-sample average to attend a four-year college because they lack information on college tuition. This position is supported only to some degree by Model 2A. This "no measure" group is substantially more likely to enter a four-year college than students who are very confident in their estimates of tuition and fees.

Models 3A through 6A generate results that change analogously to those presented in the models of Table 4 . The adjustment variables are measured for a larger group of students in these models, but this additional variation has little effect on the adjusted average probability differences between the very confident, somewhat confident, and not at all confident groups. In other words, for these comparisons the estimated probability differences are nearly the same in Tables 4 and 5. The average probability difference for the new comparison - "No measure of confidence vs. Not at all" - declines in the same way as additional adjustment variables are deployed. For all group comparisons, the measures of test scores and grades adjust away a 
larger proportion of the group differences, but all of the adjustment variables in Model 6A are needed to reduce the group differences consistently below the sizes of their corresponding standard errors. Again, how to interpret these changes in the probability differences depends on the causal structure that one is willing to assume determines these associations. We discuss some alternative positions below, after summarizing the empirical results that this descriptively motivated analysis has developed.

\section{CONCLUSIONS}

In this article, we first considered variation in specific responses to the question, "What is your best estimate of the cost of one year's tuition and mandatory fees at a public 4-year college in your state?" Consistent with prior research, we showed that ninth graders who planned to obtain some form of postsecondary training in the year after graduating high school, on average, believed that a four-year college degree at a public university in their state is much more expensive than the true levels of tuition and fees indicate. We then showed that the students most likely to attend college in the year after high school graduation were the students who were most likely to have overestimated tuition and fees.

Based on responses to the question, "How confident are you in the accuracy of your estimate of the cost of one year's tuition and mandatory fees at a public 4-year college in your state?," we then showed that the students who expressed the least confidence in the accuracy of their estimates of tuition and fees were the students who were most likely to enter college immediately after high school, either at a four-year college or at any other type of institution. 
Altogether, these results imply a perverse policy recommendation: to boost college attendance, the nation should increase tuition and fees while eroding the confidence of ninth graders that they understand how much college tuition and fees will cost. No reasonable analyst of college choices would recommend such an intervention, and, as a result, we would argue that these results raise important questions for the study of the consequences of students' beliefs about the costs of college, as well as models of educational attainment that presume such beliefs are important. The results imply that much additional work is needed to collect and analyze newer forms of data that can enable deeper modeling of students' beliefs and the consequences of their variation for patterns of educational attainment.

\section{DISCUSSION}

In this final section, we discuss two related sets of ideas: the implications of alternative assumed causal structures for interpretations of the models offered above, and how best to interpret the associations between confidence in estimates of tuition and fees and patterns of subsequent educational attainment. To ground this discussion in the substance of our findings, recall two patterns flagged above for later consideration, which we noted when interpreting the capacity of available adjustment variables to reduce the associations between confidence in estimates of tuition and fees and alternative college-entry rates. On average, male students are more confident in their estimates, but less likely to enter postsecondary education in the year after high school graduation. Relatedly, students with lower test scores and middle school grades are also more confident in their estimates, and less likely to enter college. 
How can we make sense of these two patterns? Male students could be less likely to continue on to four-year colleges for reasons unrelated to their beliefs, even though they express more confidence in their estimates because they are prone to projecting false mastery over the tuition-estimation task. Or, alternatively, male students could be less likely to continue on to four-year colleges because they have too much confidence in pessimistic ninth-grade estimates of tuition, which imply that college may not be affordable. If the latter is true, at least in part, then the elevated confidence of male students is a disadvantage because it may make them resistant to contrary information that college is more affordable than they believed during the early years of high school.

For this gender association, we do not know which of these explanations to privilege, and that is primarily because we do not know where to place confidence in cost estimates within a causal model based on extant research in this domain. For this reason, the capacity for the variable "male" to explain away some of the association between confidence and later educational attainment also does not help us to adjudicate between these explanations, and it certainly does not provide any substantial evidence for the claim that overconfident but pessimistic beliefs are harmless.

Now consider the related pattern for test scores and grades. It is reasonable to assume that students with greater numeracy skills performed better on the HSLS standardized math test given in the ninth grade, and that they probably received better math and science grades in middle school as well. Based on decades of research, it seems reasonable to assume that these same students would be more likely to continue on to postsecondary education. But why would these same students express less confidence in their estimates of tuition and fees when 
asked in the ninth grade? It seems unlikely that they lacked information on tuition and fees that students with lower test scores and weaker grades had access to.

One possibility is that these high-performing students are more likely to recognize the challenge represented by the tuition-estimation task, after first reflecting on how little reliable information is at their disposal. Because of the skills measured by test performance, they may also have the metacognition to appropriately signal a lack of confidence in response to the survey instrument (see our discussion of this literature in the introduction). In addition, they may also be more likely to remain open to accurate information in subsequent years that could give them more optimism about the affordability of college. If so, then their expressed lack of confidence in their ninth-grade estimates of tuition and fees is an advantage, not a reflection of an information deficit.

If this explanation is true, then it is not invalidated by the capacity of ninth-grade math test scores and middle school grades to explain away a large portion of the raw association between a lack of confidence in estimates of tuition and fees and the likelihood of entering postsecondary education. Rather, it is the constellation of beliefs possessed by these students that may permit them to learn throughout the course of high school that college is affordable enough that its benefits are attainable.

In the end, we are confident in one implication of these open-ended findings. To adjudicate between competing explanations such as those discussed in this section, the next step for data collection is to consider individual variability in estimates of tuition and fees, using interval elicitation, so that we can determine whether students who are confident in their estimates are also overprecise (again, see our discussion of this literature in the introduction). 
In this article, we see suggestive evidence that this may be the case, but our analysis of grouplevel variation across individuals provided no additional evidence in support of it. If such elicitation were embedded within surveys that follow students over-time, such as for a successor to the HSLS, we would be able to model how individuals' interval estimates of tuition and fees evolve as new information is sought or provided. The HSLS instrument demonstrates clearly why this research agenda is needed, even if the way it has done so was likely unforeseen by those who designed the questionnaire. 


\section{REFERENCES}

Advisory Committee on Student Financial Assistance. 2005. “The Student Aid Gauntlet: Making Access to College Simple and Certain." U.S. Department of Education, Washington, DC.

Avery, Christopher and Thomas J. Kane. 2004. "Student Perceptions of College Opportunities: The Boston Coach Program." Pp. 355-91 in College Choices: The Economics of Where to Go, When to Go, and How to Pay for It, edited by C. M. Hoxby. Chicago: University of Chicago Press.

Ben-David, Itzhak, John R. Graham, and Campbell R. Harvey. 2013. “Managerial Miscalibration." The Quarterly Journal of Economics 128:1547-84.

Bettinger, Eric P., Bridget Terry Long, Philip Oreopoulos, and Lisa Sanbonmatsu. 2012. “The Role of Application Assistance and Information in College Decisions: Results from the H\&R Block FAFSA Experiment." The Quarterly Journal of Economics 127:1205-42.

Block, Richard A. and David R. Harper. 1991. “Overconfidence in Estimation: Testing the Anchoring-and-Adjustment Hypothesis." Organizational Behavior and Human Decision Processes 49:188-207.

Bozick, Robert, Karl L. Alexander, Doris Entwisle, Susan Dauber, and Kerri Kerr. 2010. "Framing the Future: Revisiting the Place of Educational Expectations in Status Attainment." Social Forces 88:2027-52.

Breen, Richard. 1999. "Beliefs, Rational Choice, and Bayesian Learning." Rationality and Society 11:463-79.

Daniel, Kent and David Hirshleifer. 2015. “Overconfident Investors, Predictable Returns, and Excessive Trading." Journal of Economic Perspectives 29:61-88.

Dominitz, Jeff and Charles F. Manski. 1996. "Eliciting Student Expectations of the Returns to Schooling." The Journal of Human Resources 31:1-26.

Duttle, Kai. 2016. “Cognitive Skills and Confidence: Interrelations with Overestimation, Overplacement and Overprecision." Bulletin of Economic Research 68:42-55.

Dynarski, Susan M. 2003. "Does Aid Matter? Measuring the Effect of Student Aid on College Attendance and Completion." American Economic Review 93:279-88.

Goldrick-Rab, Sara. 2016. Paying the Price: College Costs, Financial Aid, and the Betrayal of the American Dream. Chicago: The University of Chicago Press.

Grodsky, Eric and Melanie T. Jones. 2007. “Real and Imagined Barriers to College Entry: Perceptions of Cost." Social Science Research 36:745-66.

Grodsky, Eric and Catherine Riegle-Crumb. 2010. “Those Who Choose and Those Who Don't: Social Background and College Orientation." Annals of the American Academy of Political and Social Science 627:14-35.

Grubb, Michael D. 2015. "Overconfident Consumers in the Marketplace.” Journal of Economic 
Perspectives 29:9-36.

Horn, Laura J., Xianglei Chen, and Chris Chapman. 2003. “Getting Ready to Pay for College: What Students and Their Parents Know About the Cost of College Tuition and What They Are Doing to Find out (NCES 2003-030)." U.S. Department of Education, National Center for Education Statistics, Washington, DC.

Hoxby, Caroline M. 2004. College Choices: The Economics of Where to Go, When to Go, and How to Pay for It. Chicago: University of Chicago Press.

Jackson, Michelle V. 2013. Determined to Succeed? Performance Versus Choice in Educational Attainment. Stanford: Stanford University Press.

Kahl, Joseph. 1953. "Educational and Occupational Aspirations of Common Man Boys." Harvard Educational Review 23:186-203.

Kane, Thomas J. 1999. The Price of Admission: Rethinking How Americans Pay for College. Washington, D.C.: Brookings.

Kruger, Justin and David Dunning. 1999. “Unskilled and Unaware of It: How Difficulties in Recognizing One's Own Incompetence Lead to Inflated Self-Assessments." Journal of Personality and Social Psychology 77:1121-34.

Luna De La Rosa, Mari 2006. “Is Opportunity Knocking? Low-Income Students' Perceptions of College and Financial Aid." American Behavioral Scientist 49:1670-86.

Manski, Charles F. 1989. "Schooling as Experimentation: A Reappraisal of the Postsecondary Dropout Phenomenon." Economics of Education Review 8:305-12.

-. 1993. "Adolescent Econometricians: How Do Youth Infer the Returns to Schooling?" in Studies of Supply and Demand in Higher Education, A National Bureau of Economic Research Project Report, edited by C. T. Clotfelter and M. Rothschild. Chicago: University of Chicago Press.

Manski, Charles F. and David A. Wise. 1983. College Choice in America. Cambridge: Harvard University Press.

McDonough, Patricia M. 1997. Choosing Colleges: How Social Class and Schools Structure Opportunity. Albany: State University of New York Press.

Moore, Don A., Ashli B. Carter, and Heather H. J. Yang. 2015. “Wide of the Mark: Evidence on the Underlying Causes of Overprecision in Judgment." Organizational Behavior and Human Decision Processes 131:110-20.

Moore, Don A. and Paul J. Healy. 2008. “The Trouble with Overconfidence.” Psychological Review 115:502-17.

Moore, Don A., Elizabeth R. Tenney, and Uriel Haran. 2015. “Overprecision in Judgment.” Pp. 182-209 in The Wiley Blackwell Handbook of Judgment and Decision Making: John Wiley \& Sons, Ltd.

Morgan, Stephen L. 2005. On the Edge of Commitment: Educational Attainment and Race in the 
United States. Stanford: Stanford University Press.

Morgan, Stephen L., Theodore S. Leenman, Jennifer J. Todd, Kentucky, and Kim A. Weeden. 2013. "Stutter-Step Models of Performance in School." Social Forces 91:1451-74.

Morgan, Stephen L., Theodore S. Leenman, Jennifer J. Todd, and Kim A. Weeden. 2013. "Occupational Plans, Beliefs About Educational Requirements, and Patterns of College Entry." Sociology of Education 86:197-217.

Oreopoulos, Philip and Ryan Dunn. 2013. "Information and College Access: Evidence from a Randomized Field Experiment." The Scandinavian Journal of Economics 115:3-26.

Perna, Laura W. 2006. “Understanding the Relationship between Information About College Prices and Financial Aid and Students' College-Related Behaviors." American Behavioral Scientist 49:1620-35.

Rouse, Cecilia E. 2004. "Low-Income Students and College Attendance: An Exploration of Income Expectations." Social Science Quarterly 85:1299-317.

Schneider, Barbara L. and David Stevenson. 1999. The Ambitious Generation: America's Teenagers, Motivated but Directionless. New Haven: Yale University Press.

Sewell, William H., Archibald O. Haller, and Alejandro Portes. 1969. “The Educational and Early Occupational Attainment Process." American Sociological Review 34:82-92.

Sewell, William H., Robert M. Hauser, Kristen W. Springer, and Taissa S. Hauser. 2004. “As We Age: A Review of the Wisconsin Longitudinal Study, 1957-2001." Research in Social Stratification and Mobility 20:3-111.

Sieck, Winston R. and Hal R. Arkes. 2005. "The Recalcitrance of Overconfidence and Its Contribution to Decision Aid Neglect." Journal of Behavioral Decision Making 18:29-53.

Soll, Jack B. and Joshua Klayman. 2004. “Overconfidence in Interval Estimates.” Journal of Experimental Psychology: Learning, Memory, and Cognition 30:299-314.

Spenner, Kenneth I. and David L. Featherman. 1978. “Achievement Ambitions.” Annual Review of Sociology 4:373-420.

Tierney, William G. and Kristan M. Venegas. 2009. "Finding Money on the Table: Information, Financial Aid, and Access to College." The Journal of Higher Education 80:363-88.

Yaniv, Ilan. 2004. “Receiving Other People's Advice: Influence and Benefit.” Organizational Behavior and Human Decision Processes 93:1-13. 
Table 1. Percentage Distributions of HSLS Ninth Graders by Self-Identified Race-Ethnicity, Gender, Family Background, and Test Score

Percent of ninth-grade students who

\begin{tabular}{|c|c|c|c|c|}
\hline & $\begin{array}{l}\text { Graduated high } \\
\text { school on time }\end{array}$ & $\begin{array}{l}\text { Graduated high } \\
\text { school on time } \\
\text { AND } \\
\text { indicated that they } \\
\text { planned to obtain } \\
\text { postsecondary } \\
\text { training in their } \\
\text { first year after high } \\
\text { school graduation }\end{array}$ & $\begin{array}{l}\text { Had "gotten } \\
\text { information about } \\
\text { the cost of tuition } \\
\text { and fees" at a } \\
\text { specific four-year } \\
\text { college }\end{array}$ & $\begin{array}{l}\text { Offered a specific } \\
\text { estimate for tuition } \\
\text { and mandatory fees } \\
\text { at an in-state four- } \\
\text { year college, among } \\
\text { those who had not } \\
\text { "gotten information } \\
\text { about the cost of } \\
\text { tuition and fees" at a } \\
\text { specific four-year } \\
\text { college }\end{array}$ \\
\hline \multicolumn{5}{|l|}{ Race-ethnicity } \\
\hline White non-Hispanic & 91.2 & 63.1 & 10.4 & 78.9 \\
\hline Black of African American & 82.1 & 57.4 & 13.2 & 80.2 \\
\hline Hispanic & 83.6 & 54.0 & 8.3 & 78.2 \\
\hline Asian or NHOPI & 92.1 & 63.2 & 14.1 & 77.8 \\
\hline American Indian & 80.7 & 50.9 & 10.1 & 77.6 \\
\hline \multicolumn{5}{|l|}{ Gender } \\
\hline Female & 89.7 & 65.7 & 10.0 & 76.2 \\
\hline Male & 85.6 & 53.7 & 11.4 & 82.1 \\
\hline \multicolumn{5}{|c|}{ Parent/guardian high level of education } \\
\hline High school or less & 82.0 & 50.5 & 9.2 & 78.4 \\
\hline Some postsecondary education & 87.5 & 57.6 & 10.2 & 78.9 \\
\hline Bachelor's degree or more & 94.3 & 71.6 & 12.0 & 79.2 \\
\hline \multicolumn{5}{|l|}{ Family income } \\
\hline 1st quartile & 79.6 & 49.2 & 9.8 & 74.7 \\
\hline 2nd quartile & 88.2 & 57.9 & 10.1 & 82.4 \\
\hline 3rd quartile & 93.2 & 68.1 & 9.7 & 79.3 \\
\hline 4th quartile & 96.6 & 74.2 & 13.4 & 79.7 \\
\hline \multicolumn{5}{|l|}{ Math test score } \\
\hline 1st quartile & 76.4 & 42.6 & 10.2 & 76.4 \\
\hline 2nd quartile & 88.0 & 56.0 & 8.6 & 76.6 \\
\hline 3rd quartile & 94.0 & 70.2 & 11.3 & 79.9 \\
\hline 4th quartile & 96.7 & 77.8 & 12.1 & 81.9 \\
\hline Total & 87.6 & 59.7 & 10.6 & 78.8 \\
\hline Unweighted N & 16,044 & 16,044 & 10,167 & 9,004 \\
\hline
\end{tabular}

Offered a specific estimate for tuition at an in-state fouryear college, among those who had not gotten information about the cost of tuition and fees" at a fic four-year college
Race-ethnicity
White non-Hispanic

91.2

82.1

89.7

Female

Parent/guardian high level of education

High school or less

Family income

1st quartile

2nd quartile

3rd quartile

Source: High School Longitudinal Study of 2009

Notes: Results are weighted by the appropriate panel weight. The full sample (unweighted $\mathrm{N}=16,044$ ) is used as the denominator for columns 1 and 2. For column 3, we then excluded from the denominator those who were not on-time high school graduates who planned to obtain postsecondary education. For column 4, we then further excluded from the denominator those who had "gotten information."
Among on-time high school graduates who indicated in the ninth grade that they planned to obtain postsecondary training in their first year after high school graduation, percent of ninth graders who 
Table 2. Distributions of Students' Estimates of Tuition and Fees at a Public Four-Year College in Their State

\begin{tabular}{|c|c|c|c|c|c|c|}
\hline & $N$ & $\begin{array}{c}10^{\text {th }} \\
\text { Percentile }\end{array}$ & $\begin{array}{c}25^{\text {th }} \\
\text { Percentile }\end{array}$ & Median & $\begin{array}{c}75^{\text {th }} \\
\text { Percentile }\end{array}$ & $\begin{array}{l}90^{\text {th }} \\
\text { Percentile }\end{array}$ \\
\hline \multicolumn{7}{|c|}{ Estimate of tuition and mandatory fees } \\
\hline All students who offer a number & 7,035 & 2,000 & 5,000 & 15,000 & 30,000 & 50,000 \\
\hline \multicolumn{7}{|c|}{ By confidence level in offered number: } \\
\hline "Not at all confident" & 2,104 & 2,000 & 5,000 & 12,000 & 30,000 & 50,000 \\
\hline "Somewhat confident" & 4,145 & 2,000 & 5,000 & 15,000 & 30,000 & 50,000 \\
\hline "Very confident" & 749 & 1,000 & 4,500 & 10,000 & 30,000 & 50,000 \\
\hline \multicolumn{7}{|c|}{$\begin{array}{l}\text { Estimate minus state average of true tuition } \\
\text { and fees }\end{array}$} \\
\hline All students who offer a number & 7,035 & $-5,336$ & $-1,734$ & 7,357 & 22,672 & 42,357 \\
\hline \multicolumn{7}{|c|}{ By confidence level in offered number: } \\
\hline "Not at all confident" & 2,104 & $-5,410$ & $-2,226$ & 5,450 & 20,480 & 42,672 \\
\hline "Somewhat confident" & 4,145 & $-5,116$ & $-1,328$ & 8,574 & 23,450 & 41,274 \\
\hline "Very confident" & 749 & $-5,788$ & $-2,508$ & 4,236 & 20,684 & 43,450 \\
\hline
\end{tabular}

Source: See Table 1.

Notes: Results are weighted by the appropriate panel weight. For the rows that divide the sample by level of confidence, 37 respondents who did not answer the confidence question were excluded. 
Table 3. Multinomial Logit Models for Postsecondary Enrollment

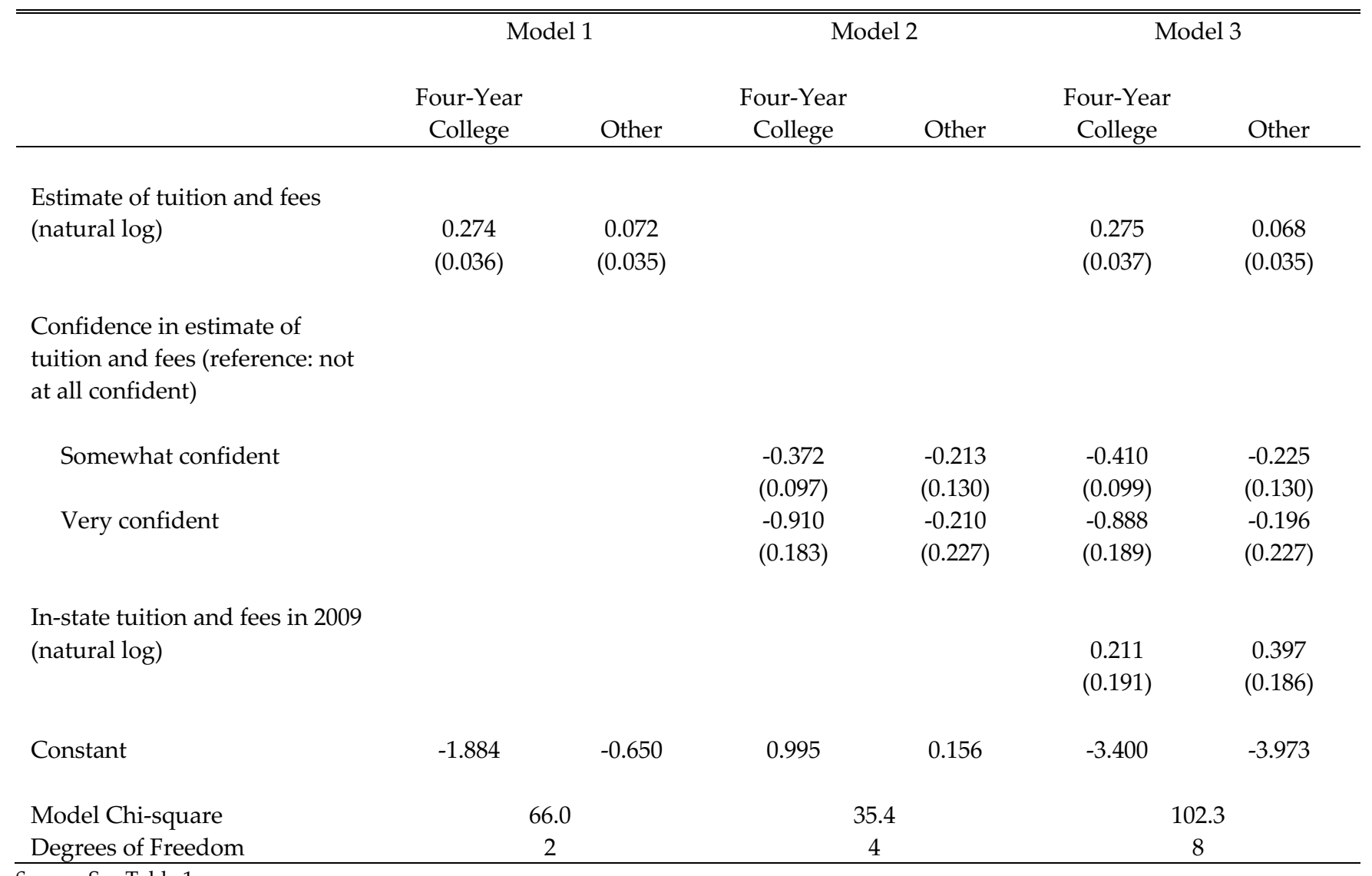

Source: See Table 1.

Notes: Results are weighted by the appropriate panel weight (unweighted $N=6,947$ ). Standard errors are in parentheses. 
Table 4. Average Probability Differences in Postsecondary Enrollment Associated with Estimates of Tuition and Fee and With Confidence, Based on Multinomial Logit Models with Alternative Sets of Adjustment Variables

\begin{tabular}{|c|c|c|c|c|c|}
\hline Model & $\begin{array}{l}\text { Four-Year } \\
\text { College }\end{array}$ & Other & None & $\begin{array}{c}\text { Model } \\
\text { Chi-Square }\end{array}$ & df \\
\hline $\begin{array}{l}\text { 1. No adjustment variables (see Table } 3 \text { ) } \\
\text { Estimate of tuition and fees (natural log) }\end{array}$ & $\begin{array}{c}0.058 \\
(0.007)\end{array}$ & $\begin{array}{l}-0.020 \\
(0.005)\end{array}$ & $\begin{array}{l}-0.038 \\
(0.006)\end{array}$ & 66.0 & 2 \\
\hline $\begin{array}{l}\text { 2. No adjustment variables (see Table } 3 \text { ) } \\
\text { Very confident vs. Not at all }\end{array}$ & $\begin{array}{l}-0.196 \\
(0.034)\end{array}$ & $\begin{array}{c}0.072 \\
(0.039)\end{array}$ & $\begin{array}{c}0.124 \\
(0.037)\end{array}$ & 35.4 & 4 \\
\hline Somewhat confident vs. Not at all & $\begin{array}{l}-0.066 \\
(0.020)\end{array}$ & $\begin{array}{l}0.008 \\
(0.020)\end{array}$ & $\begin{array}{c}0.057 \\
(0.017)\end{array}$ & & \\
\hline $\begin{array}{l}\text { 3. All variables in Model } 1 \text { and } 2+\text { state } \\
\text { average of true tuition and fees (see Table } 3 \text { ) } \\
\text { Estimate of tuition and fees (natural log) }\end{array}$ & $\begin{array}{c}0.058 \\
(0.007)\end{array}$ & $\begin{array}{l}-0.021 \\
(0.005)\end{array}$ & $\begin{array}{l}-0.037 \\
(0.006)\end{array}$ & 102.3 & 8 \\
\hline Somewhat confident vs. Not at all & $\begin{array}{c}-0.188 \\
(0.035) \\
-0.071 \\
(0.020)\end{array}$ & $\begin{array}{c}0.072 \\
(0.039) \\
0.010 \\
(0.020)\end{array}$ & $\begin{array}{c}0.116 \\
(0.037) \\
0.061 \\
(0.017)\end{array}$ & & \\
\hline $\begin{array}{l}\text { 4. Model } 3+\text { SES, race-ethnicity, gender, } \\
\text { urbanicity, region, private school }\end{array}$ & & & & 748.9 & 44 \\
\hline Estimate of tuition and fees (natural log) & $\begin{array}{c}0.034 \\
(0.006)\end{array}$ & $\begin{array}{l}-0.012 \\
(0.005)\end{array}$ & $\begin{array}{l}-0.023 \\
(0.005)\end{array}$ & & \\
\hline Very confident vs. Not at all & $\begin{array}{l}-0.106 \\
(0.029)\end{array}$ & $\begin{array}{c}0.051 \\
(0.036)\end{array}$ & $\begin{array}{c}0.055 \\
(0.032)\end{array}$ & & \\
\hline Somewhat confident vs. Not at all & $\begin{array}{r}-0.022 \\
(0.018)\end{array}$ & $\begin{array}{l}-0.005 \\
(0.020)\end{array}$ & $\begin{array}{c}0.027 \\
(0.018)\end{array}$ & & \\
\hline $\begin{array}{l}\text { 5. Model } 3+\text { Math test score in ninth grade, } \\
\text { math and science grades from eighth grade }\end{array}$ & & & & 556.3 & 14 \\
\hline Estimate of tuition and fees (natural log) & $\begin{array}{c}0.025 \\
(0.006)\end{array}$ & $\begin{array}{l}-0.008 \\
(0.005)\end{array}$ & $\begin{array}{l}-0.017 \\
(0.005)\end{array}$ & & \\
\hline Very confident vs. Not at all & $\begin{array}{l}-0.046 \\
(0.032)\end{array}$ & $\begin{array}{c}0.016 \\
(0.036)\end{array}$ & $\begin{array}{c}0.030 \\
(0.034)\end{array}$ & & \\
\hline Somewhat confident vs. Not at all & $\begin{array}{l}-0.020 \\
(0.019)\end{array}$ & $\begin{array}{l}-0.010 \\
(0.021)\end{array}$ & $\begin{array}{c}0.030 \\
(0.017)\end{array}$ & & \\
\hline $\begin{array}{l}\text { 6. Model } 3+\text { All adjustment variables from } \\
\text { Models } 4 \text { and } 5\end{array}$ & & & & 1092.3 & 50 \\
\hline Estimate of tuition and fees (natural log) & $\begin{array}{c}0.016 \\
(0.005)\end{array}$ & $\begin{array}{l}-0.005 \\
(0.005)\end{array}$ & $\begin{array}{l}-0.011 \\
(0.005)\end{array}$ & & \\
\hline Very confident vs. Not at all & $\begin{array}{l}-0.029 \\
(0.029)\end{array}$ & $\begin{array}{c}0.020 \\
(0.035)\end{array}$ & $\begin{array}{c}0.008 \\
(0.032)\end{array}$ & & \\
\hline Somewhat confident vs. Not at all & $\begin{array}{c}0.003 \\
(0.018)\end{array}$ & $\begin{array}{l}-0.014 \\
(0.020)\end{array}$ & $\begin{array}{c}0.012 \\
(0.018)\end{array}$ & & \\
\hline
\end{tabular}

Source: See Table 1.

Notes: Results are weighted by the appropriate panel weight (unweighted $N=6,947)$. Average probability differences are calculated casewise and then averaged over the estimation sample, using Stata's margins, $d y d x()$ command. Standard errors for the probability differences are in parentheses. See Appendix A, Table A5, for the coefficients of the estimated models. 
Table 5. Average Probability Differences Based on Alternative Multinomial Logit Models that Include Students Who Declined to Offer Estimates of Tuition and Fees and/or Confidence in Their Estimates

\begin{tabular}{|c|c|c|c|c|c|}
\hline \multirow[b]{2}{*}{ Model } & \multicolumn{2}{|l|}{ Four-Year } & \multicolumn{3}{|c|}{ Model } \\
\hline & College & Other & None & & dt \\
\hline 2A. No adjustment variables & & & & 48.8 & 6 \\
\hline \multirow[t]{2}{*}{ Very confident vs. Not at all } & -0.196 & 0.072 & 0.124 & & \\
\hline & $(0.034)$ & $(0.039)$ & $(0.037)$ & & \\
\hline \multirow[t]{2}{*}{ Somewhat confident vs. Not at all } & -0.066 & 0.008 & 0.057 & & \\
\hline & $(0.020)$ & $(0.020)$ & $(0.017)$ & & \\
\hline \multirow[t]{2}{*}{ No measure of confidence vs. Not at all } & -0.114 & 0.045 & 0.068 & & \\
\hline & $(0.023)$ & $(0.023)$ & $(0.023)$ & & \\
\hline
\end{tabular}

3A. Model 2A + state average of true tuition and fees

Very confident vs. Not at all

$\begin{array}{ccc}-0.196 & 0.073 & 0.123 \\ (0.034) & (0.039) & (0.037) \\ -0.065 & 0.008 & 0.057 \\ (0.020) & (0.020) & (0.017) \\ -0.114 & 0.045 & 0.069 \\ (0.023) & (0.023) & (0.023)\end{array}$

54.29

8

Somewhat confident vs. Not at all

$(0.023)$

888.9

44

urbanicity, region, private school

Very confident vs. Not at all

$\begin{array}{ccc}-0.105 & 0.056 & 0.049 \\ (0.030) & (0.038) & (0.032) \\ -0.016 & -0.005 & 0.022 \\ (0.019) & (0.020) & (0.018) \\ -0.063 & 0.026 & 0.036 \\ (0.020) & (0.024) & (0.023)\end{array}$

5A. Model 3A + Math test score in ninth grade, math and science grades from eighth grade

Very confident vs. Not at all

$\begin{array}{ccc}-0.042 & 0.012 & 0.026 \\ (0.032) & (0.021) & (0.034) \\ -0.015 & -0.012 & 0.027 \\ (0.019) & (0.021) & (0.017) \\ -0.024 & 0.010 & 0.014 \\ (0.020) & (0.024) & (0.021)\end{array}$

6A. Model $3+$ All adjustment variables from Models 4 and 5

Very confident vs. Not at all

$\begin{array}{ccc}-.024 & 0.024 & 0.001 \\ (0.029) & (0.037) & (0.032) \\ 0.006 & -0.014 & 0.007 \\ (0.018) & (0.021) & (0.018) \\ -0.009 & 0.007 & 0.002 \\ (0.019) & (0.024) & (0.022)\end{array}$

Source: See Table 1

Notes: Results are weighted by the appropriate panel weight (unweighted $N=8,939$ ). Average probability differences are calculated casewise and then averaged over the estimation sample, using Stata's margins, $d y d x()$ command. Standard errors for the probability differences are in parentheses. See Appendix A, Table A6, for the coefficients of the estimated models. 


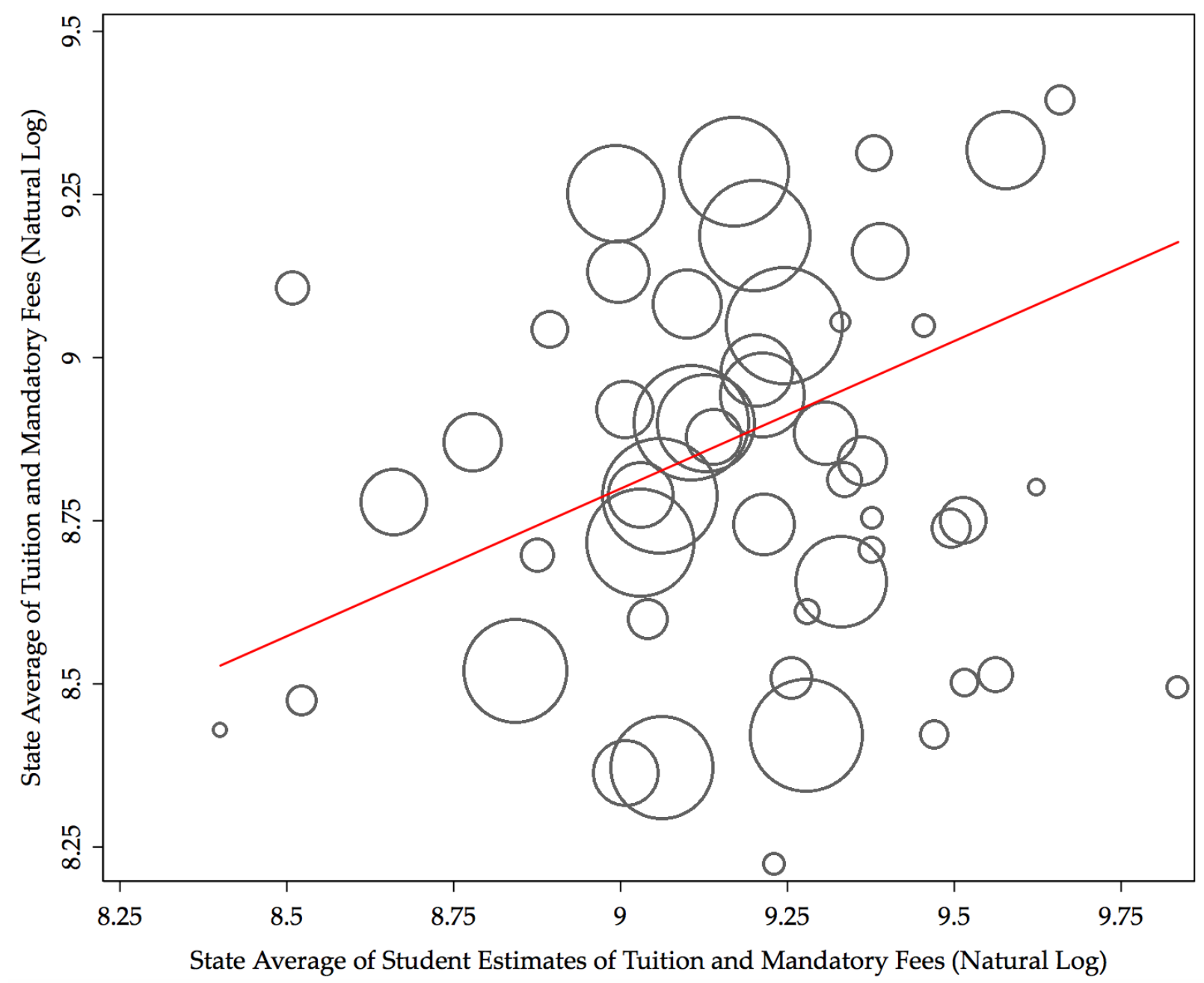

Figure 1. True Tuition and Fees (y axis) by Student Estimates (x axis), Averaged at the State Level, with Weighted Least Squares Fitted Values (red line) 


\title{
Appendix A
}

\author{
for \\ Overconfidence and Uncertainty: \\ High School Students' Beliefs About College Tuition \\ and Their Subsequent College-Entry Rates
}

\section{Contents}

I. Supplementary Results $\ldots \ldots \ldots \ldots \ldots \ldots \ldots \ldots \ldots \ldots \ldots$ Pages A-1 - A-13

II. Description of Variable Construction $\ldots \ldots \ldots \ldots \ldots \ldots \ldots \ldots$ Pages A-14 - A-21 


\section{SUPPLEMENTARY RESULTS}

Table A1. Means and Standard Deviations of the Adjustment Variables for the Analysis

\begin{tabular}{|c|c|c|c|c|}
\hline & \multicolumn{2}{|c|}{$\begin{array}{c}\text { Full Panel Sample } \\
\text { (Unweighted } N=16,044)\end{array}$} & \multicolumn{2}{|c|}{$\begin{array}{l}\text { College Bound Sample } \\
\text { (Unweighted } N=10,167 \text { ) }\end{array}$} \\
\hline & Mean & $\mathrm{SD}$ & Mean & $\mathrm{SD}$ \\
\hline \multicolumn{5}{|l|}{ Family Background } \\
\hline Family income (natural logarithm of dollars) & 10.88 & 0.741 & 11.00 & 0.732 \\
\hline Parent/guardian years of education (most & & & & \\
\hline highly educated parent/guardian) & 14.06 & 2.563 & 14.47 & 2.603 \\
\hline $\begin{array}{l}\text { Parent/guardian years of education (other } \\
\text { parent/guardian) }\end{array}$ & 12.48 & 1.936 & 12.79 & 2.011 \\
\hline $\begin{array}{l}\text { Parent/guardian occupational standing } \\
\text { (highest SEI score) }\end{array}$ & 56.06 & 18.625 & 57.92 & 18.277 \\
\hline $\begin{array}{l}\text { Parent/guardian occupational standing } \\
\text { (other SEI score) }\end{array}$ & 37.98 & 15.561 & 39.57 & 16.20 \\
\hline \multicolumn{5}{|l|}{ Gender } \\
\hline Male & 0.50 & & 0.45 & \\
\hline Female & 0.50 & & 0.55 & \\
\hline \multicolumn{5}{|l|}{ Race } \\
\hline White non-Hispanic & 0.52 & & 0.55 & \\
\hline Black or African-American & 0.17 & & 0.16 & \\
\hline Hispanic & 0.22 & & 0.20 & \\
\hline Asian or NHOPI & 0.05 & & 0.06 & \\
\hline American Indian & 0.04 & & 0.03 & \\
\hline \multicolumn{5}{|l|}{ Urbanicity } \\
\hline City & 0.32 & & 0.31 & \\
\hline Suburb & 0.33 & & 0.34 & \\
\hline Town & 0.12 & & 0.11 & \\
\hline Rural & 0.23 & & 0.24 & \\
\hline \multicolumn{5}{|l|}{ Region } \\
\hline Northeast & 0.17 & & 0.17 & \\
\hline Midwest & 0.22 & & 0.23 & \\
\hline South & 0.38 & & 0.39 & \\
\hline West & 0.23 & & 0.22 & \\
\hline \multicolumn{5}{|l|}{ Type of high school } \\
\hline Public & 0.93 & & 0.91 & \\
\hline Catholic & 0.04 & & 0.05 & \\
\hline Other private & 0.03 & & 0.04 & \\
\hline \multicolumn{5}{|l|}{ Academic performance } \\
\hline Standardized math test (fall of $9^{\text {th }}$ grade) & 39.60 & 11.747 & 42.36 & 11.283 \\
\hline Self-reported math grade $\left(0-4,8^{\text {th }}\right.$ grade $)$ & 2.96 & 0.979 & 3.17 & 0.879 \\
\hline Self-reported science grade $\left(0-4,8^{\text {th }}\right.$ grade $)$ & 3.07 & 0.914 & 3.29 & 0.792 \\
\hline
\end{tabular}

Source: See Table 1.

Notes: Results are weighted by the appropriate panel weight. 
Table A2. OLS Regression Models for the Prediction of the Logarithm of Student Estimates of Tuition and Mandatory Fees at a Public Four-Year College in Their State

\begin{tabular}{|c|c|c|c|c|}
\hline & Model 1 & Model 2 & Model 3 & Model 4 \\
\hline $\begin{array}{l}\text { In-state tuition and fees in } 2009 \text { in student's } \\
\text { state of residence (natural logarithm of dollars) }\end{array}$ & $\begin{array}{c}0.188 \\
(0.098)\end{array}$ & $\begin{array}{c}0.034 \\
(0.120)\end{array}$ & $\begin{array}{c}0.169 \\
(0.090)\end{array}$ & $\begin{array}{c}0.048 \\
(0.122)\end{array}$ \\
\hline \multicolumn{5}{|l|}{ Family Background } \\
\hline Family income (natural logarithm of dollars) & & $\begin{array}{c}0.108 \\
(0.050)\end{array}$ & & $\begin{array}{c}0.061 \\
(0.046)\end{array}$ \\
\hline $\begin{array}{l}\text { Parent/guardian years of education (most } \\
\text { highly educated parent/guardian) }\end{array}$ & & $\begin{array}{c}0.006 \\
(0.016)\end{array}$ & & $\begin{array}{l}-0.001 \\
(0.0106)\end{array}$ \\
\hline $\begin{array}{l}\text { Parent/guardian years of education (other } \\
\text { parent/guardian) }\end{array}$ & & $\begin{array}{c}0.040 \\
(0.020)\end{array}$ & & $\begin{array}{c}0.024 \\
(0.019)\end{array}$ \\
\hline $\begin{array}{l}\text { Parent/guardian occupational standing } \\
\text { (highest SEI score) }\end{array}$ & & $\begin{array}{c}0.003 \\
(0.002)\end{array}$ & & $\begin{array}{c}0.003 \\
(0.002)\end{array}$ \\
\hline $\begin{array}{l}\text { Parent/guardian occupational standing } \\
\text { (other SEI score) }\end{array}$ & & $\begin{array}{l}<0.001 \\
(0.002)\end{array}$ & & $\begin{array}{l}-0.001 \\
(0.002)\end{array}$ \\
\hline Female & & $\begin{array}{l}-0.058 \\
(0.057)\end{array}$ & & $\begin{array}{l}-0.051 \\
(0.055)\end{array}$ \\
\hline \multicolumn{5}{|l|}{ Race (reference: White non-Hispanic) } \\
\hline Black of African-American & & $\begin{array}{l}-0.129 \\
(0.089)\end{array}$ & & $\begin{array}{r}-0.0116 \\
(0.089)\end{array}$ \\
\hline Hispanic & & $\begin{array}{l}-0.030 \\
(0.074)\end{array}$ & & $\begin{array}{l}0.0239 \\
(0.075)\end{array}$ \\
\hline Asian or NHOPI & & $\begin{array}{c}0.118 \\
(0.082)\end{array}$ & & $\begin{array}{l}0.0269 \\
(0.083)\end{array}$ \\
\hline American Indian & & $\begin{array}{c}0.049 \\
(0.122)\end{array}$ & & $\begin{array}{c}0.102 \\
(0.119)\end{array}$ \\
\hline \multicolumn{5}{|l|}{ Urbanicity (reference: City) } \\
\hline Suburb & & $\begin{array}{c}0.135 \\
(0.062)\end{array}$ & & $\begin{array}{c}0.126 \\
(0.062)\end{array}$ \\
\hline Town & & $\begin{array}{l}-0.038 \\
(0.093)\end{array}$ & & $\begin{array}{l}-0.027 \\
(0.092)\end{array}$ \\
\hline Rural & & $\begin{array}{c}0.185 \\
(0.067)\end{array}$ & & $\begin{array}{c}0.198 \\
(0.068)\end{array}$ \\
\hline \multicolumn{5}{|l|}{ Region (reference: Northeast) } \\
\hline Midwest & & $\begin{array}{l}-0.005 \\
(0.077)\end{array}$ & & $\begin{array}{l}-0.001 \\
(0.072)\end{array}$ \\
\hline South & & $\begin{array}{l}-0.082 \\
(0.095)\end{array}$ & & $\begin{array}{l}-0.095 \\
(0.092)\end{array}$ \\
\hline West & & $\begin{array}{l}-0.059 \\
(0.100)\end{array}$ & & $\begin{array}{l}-0.047 \\
(0.097)\end{array}$ \\
\hline
\end{tabular}


Type of high school (reference: Public)

Catholic

0.285

0.287

$(0.050)$

$(0.051)$

Other private

0.204

0.192

(0.065)

(0.064)

Academic performance

Standardized math test (fall of ninth grade)

Self-reported math grade (eighth grade)

$(0.003)$

0.017

Self-reported science grade (eighth grade)

0.040

$(0.003)$

(0.039)

0.033

0.087

(0.038)

(0.040)

0.073

Constant

7.642

7.041

6.411

(0.041)

R-squared

0.001

0.033

0.042

6.575

Observations

6,983

6,983

6,983

0.056

Source: See Table 1.

Notes: Results are weighted by the appropriate panel weight. Standard errors in parentheses. 
Average probability differences implied by the model for each outcome category:

\begin{tabular}{|c|c|c|c|c|}
\hline & $\begin{array}{l}\text { Ordered Logit } \\
\text { Model }\end{array}$ & $\begin{array}{l}\text { Not at all } \\
\text { confident }\end{array}$ & $\begin{array}{l}\text { Somewhat } \\
\text { confident }\end{array}$ & $\begin{array}{c}\text { Very } \\
\text { confident }\end{array}$ \\
\hline $\begin{array}{l}\text { Student estimate of tuition and fees at a public } \\
\text { four-year college (natural logarithm of dollars) }\end{array}$ & $\begin{array}{c}0.0502 \\
(0.0303)\end{array}$ & $\begin{array}{l}-0.00965 \\
(0.00583)\end{array}$ & $\begin{array}{c}0.00456 \\
(0.00279)\end{array}$ & $\begin{array}{c}0.00509 \\
(0.00306)\end{array}$ \\
\hline $\begin{array}{l}\text { In-state tuition and fees in } 2009 \text { in student's } \\
\text { state of residence (natural logarithm of dollars) }\end{array}$ & $\begin{array}{c}0.126 \\
(0.157)\end{array}$ & $\begin{array}{l}-0.0241 \\
(0.0302)\end{array}$ & $\begin{array}{c}0.0114 \\
(0.0143)\end{array}$ & $\begin{array}{c}0.0127 \\
(0.0160)\end{array}$ \\
\hline \multicolumn{5}{|l|}{ Family Background } \\
\hline Family income (natural logarithm of dollars) & $\begin{array}{c}-0.131 \\
(0.0663)\end{array}$ & $\begin{array}{c}0.0251 \\
(0.0127)\end{array}$ & $\begin{array}{c}-0.0119 \\
(0.00587)\end{array}$ & $\begin{array}{c}-0.0132 \\
(0.00686)\end{array}$ \\
\hline $\begin{array}{l}\text { Parent/guardian years of education (most } \\
\text { highly educated parent/guardian) }\end{array}$ & $\begin{array}{l}-0.00528 \\
(0.0193)\end{array}$ & $\begin{array}{c}0.00101 \\
(0.00506)\end{array}$ & $\begin{array}{l}-0.000479 \\
(0.00241)\end{array}$ & $\begin{array}{r}-0.000535 \\
(0.00196)\end{array}$ \\
\hline $\begin{array}{l}\text { Parent/guardian years of education (other } \\
\text { parent/guardian) }\end{array}$ & $\begin{array}{l}-0.0227 \\
(0.0263)\end{array}$ & $\begin{array}{c}0.00436 \\
(0.00506)\end{array}$ & $\begin{array}{l}-0.00206 \\
(0.00241)\end{array}$ & $\begin{array}{l}-0.00230 \\
(.00266)\end{array}$ \\
\hline $\begin{array}{l}\text { Parent/guardian occupational standing } \\
\text { (highest SEI score) }\end{array}$ & $\begin{array}{c}0.00161 \\
(0.00253)\end{array}$ & $\begin{array}{l}-0.000309 \\
(0.000486)\end{array}$ & $\begin{array}{c}0.000146 \\
(0.000230)\end{array}$ & $\begin{array}{c}0.000163 \\
(0.000257)\end{array}$ \\
\hline $\begin{array}{l}\text { Parent/guardian occupational standing } \\
\quad \text { (other SEI score) }\end{array}$ & $\begin{array}{l}-0.000951 \\
(0.00248)\end{array}$ & $\begin{array}{c}0.000183 \\
(0.000477)\end{array}$ & $\begin{array}{r}-0.0000864 \\
(0.000230)\end{array}$ & $\begin{array}{l}-0.0000963 \\
(0.000257)\end{array}$ \\
\hline Female & $\begin{array}{c}-0.477 \\
(0.0784)\end{array}$ & $\begin{array}{c}0.0912 \\
(0.0147)\end{array}$ & $\begin{array}{c}-0.0425 \\
(0.00718)\end{array}$ & $\begin{array}{c}-0.0487 \\
(0.00845)\end{array}$ \\
\hline \multicolumn{5}{|l|}{ Race (reference: White non-Hispanic) } \\
\hline Black of African-American & $\begin{array}{c}0.428 \\
(0.114)\end{array}$ & $\begin{array}{l}-0.0791 \\
(0.0198)\end{array}$ & $\begin{array}{c}0.0328 \\
(0.00655)\end{array}$ & $\begin{array}{c}0.0463 \\
(0.0140)\end{array}$ \\
\hline Hispanic & $\begin{array}{c}0.168 \\
(0.127)\end{array}$ & $\begin{array}{l}-0.0329 \\
(0.0242)\end{array}$ & $\begin{array}{c}0.0163 \\
(0.0111)\end{array}$ & $\begin{array}{c}0.0165 \\
(0.0131)\end{array}$ \\
\hline Asian or NHOPI & $\begin{array}{l}0.0957 \\
(0.120)\end{array}$ & $\begin{array}{l}-0.0190 \\
(0.0215)\end{array}$ & $\begin{array}{l}0.00981 \\
(0.0107)\end{array}$ & $\begin{array}{l}0.00915 \\
(0.0108)\end{array}$ \\
\hline American Indian & $\begin{array}{c}0.173 \\
(0.150)\end{array}$ & $\begin{array}{l}-0.0338 \\
(0.0285)\end{array}$ & $\begin{array}{c}0.0168 \\
(0.0129)\end{array}$ & $\begin{array}{c}0.0171 \\
(0.0156)\end{array}$ \\
\hline Urbanicity (reference: City) & & & & \\
\hline Suburb & $\begin{array}{c}0.0833 \\
(0.0930)\end{array}$ & $\begin{array}{l}-0.0161 \\
(0.0181)\end{array}$ & $\begin{array}{c}0.00781 \\
(0.00894)\end{array}$ & $\begin{array}{c}0.00832 \\
(0.00918)\end{array}$ \\
\hline Town & $\begin{array}{l}0.0642 \\
(0.139)\end{array}$ & $\begin{array}{l}-0.0125 \\
(0.0268)\end{array}$ & $\begin{array}{l}0.00611 \\
(0.0129)\end{array}$ & $\begin{array}{l}0.00636 \\
(0.0139)\end{array}$ \\
\hline Rural & $\begin{array}{c}0.107 \\
(0.110)\end{array}$ & $\begin{array}{l}-0.0205 \\
(0.0211)\end{array}$ & $\begin{array}{l}0.00980 \\
(0.0101)\end{array}$ & $\begin{array}{c}0.0107 \\
(0.0111)\end{array}$ \\
\hline $\begin{array}{l}\text { Region (reference: Northeast) } \\
\text { Midwest }\end{array}$ & -0.234 & 0.0458 & -0.0227 & -0.0231 \\
\hline
\end{tabular}




\begin{tabular}{|c|c|c|c|c|}
\hline \multirow{3}{*}{ South } & $(0.112)$ & $(0.0215)$ & (0.0103) & $(0.0116)$ \\
\hline & 0.0138 & -0.00257 & 0.00108 & 0.00149 \\
\hline & $(0.131)$ & $(0.0243)$ & $(0.0103)$ & $(0.0140)$ \\
\hline \multirow[t]{2}{*}{ West } & -0.143 & 0.0274 & -0.0129 & -0.0145 \\
\hline & $(0.156)$ & $(0.0298)$ & $(0.0139)$ & $(0.0160)$ \\
\hline \multicolumn{5}{|l|}{ Type of high school (reference: public) } \\
\hline \multirow{2}{*}{ Catholic } & 0.0401 & -0.00763 & 0.00350 & 0.00412 \\
\hline & $(0.102)$ & $(0.0194)$ & $(0.00873)$ & $(0.0107)$ \\
\hline \multirow[t]{2}{*}{ Other private } & -0.137 & 0.0269 & -0.0137 & -0.0132 \\
\hline & $(0.135)$ & $(0.0272)$ & $(0.0147)$ & $(0.0125)$ \\
\hline \multicolumn{5}{|l|}{ Academic performance } \\
\hline \multirow[t]{2}{*}{ Standardized math test (fall of ninth grade) } & -0.0265 & 0.00509 & -0.00240 & -0.00268 \\
\hline & $(0.00462)$ & $(0.000870)$ & $(0.000434)$ & $(0.000481)$ \\
\hline \multirow[t]{2}{*}{ Self-reported math grade (eighth grade) } & -0.0398 & 0.007655 & -0.00362 & -000404 \\
\hline & $(0.0537)$ & $(0.0103)$ & $(0.00486)$ & $(0.00545)$ \\
\hline \multirow[t]{2}{*}{ Self-reported science grade (eighth grade) } & -0.0359 & 0.00689 & -0.00326 & -0.00363 \\
\hline & $(0.0552)$ & $(0.0106)$ & $(0.00501)$ & $(0.00560)$ \\
\hline Cut point 1 & -2.777 & & & \\
\hline Cut point 2 & 0.330 & & & \\
\hline Model Chi-square & 204.18 & & & \\
\hline Degrees of Freedom & 23 & & & \\
\hline
\end{tabular}

Source: See Table 1.

Notes: Results are weighted by the appropriate panel weight. $N=6,947$. Standard errors in parentheses. 
Table A4. College Entry Patterns in the Fall After On-Time High School Graduation by First-Year High School Plans for the Year Following High School Graduation

\begin{tabular}{lccccc} 
& \multicolumn{2}{c}{$\begin{array}{c}\text { College-bound } \\
\text { and }\end{array}$} & & & \\
\cline { 2 - 4 } & $\begin{array}{c}\text { Has not gotten } \\
\text { information on } \\
\text { tuition costs at } \\
\text { a specific four- } \\
\text { year college }\end{array}$ & $\begin{array}{c}\text { Has gotten } \\
\text { information on } \\
\text { tuition costs at } \\
\text { a specific four- } \\
\text { year college }\end{array}$ & $\begin{array}{c}\text { Not sure of } \\
\text { plans }\end{array}$ & $\begin{array}{c}\text { No plans to } \\
\text { attend } \\
\text { postsecondary } \\
\text { education }\end{array}$ & $\begin{array}{c}\text { Did not } \\
\text { graduate from } \\
\text { high school } \\
\text { on-time }\end{array}$ \\
\hline $\begin{array}{l}\text { Attend four-year college } \\
\text { Attend other type of post- }\end{array}$ & 48.2 & 59.0 & 35.9 & 23.4 & 3.7 \\
$\begin{array}{l}\text { Necondary institution } \\
\text { No postsecondary }\end{array}$ & 26.0 & 21.6 & 27.6 & 27.8 & 12.4 \\
Total & 25.8 & 19.4 & 36.5 & 48.8 & 84.0 \\
Unweighted N & 100.0 & 100.0 & 100.0 & 100.0 & 100.0 \\
\hline
\end{tabular}

Source: See Table 1.

Notes: Results are weighted by the appropriate panel weight. The total $N$ for the analysis reported in this table is 15,917 , which excludes the 127 students who had missing information on college attendance from the full sample of 16,044. However, students who did not offer specific plans are excluded from the table (Unweighted $N=353$ ); their distribution was closest to the "Not sure of plans" group and "No plans" group, with 27.2, 25.1, and 47.8 percentages corresponding to the rows of the table. We could further divide the 8,939 students in the first column into two groups: the 6,983 students who provided a numerical estimate of tuition and fees and also confidence and the 1,956 students who did not. For the first subgroup, the corresponding percentages for the table would be 49.2, 25.4, and 25.4. For the second subgroup, the percentages would be 44.2, 28.3, and 27.6. As these differences reveal, the willingness to provide an estimate of tuition and fees and then confidence has a small positive relationship with subsequent postsecondary enrollment, but one which is much smaller in magnitude than the other differences across the columns of this table. 
Table A5. Multinomial Logit Models for Postsecondary Enrollment (Full Models on Which Tables 3 and 4 are Based)

$\begin{array}{llll}\text { Model } 2 & \text { Model 3 } & \text { Model 4 } & \text { Model 5 } 6\end{array}$

Four-year Other Four-year Other Four-year Other Four-year $\quad$ Other Four-year Other

Confidence in estimate of tuition and fees
(reference: not at all confident)

Somewhat confident

$\begin{array}{cc}-0.372 & -0.214 \\ (0.0972) & (0.130) \\ -0.910 & -0.210 \\ (0.183) & (0.227)\end{array}$

$\begin{array}{cc}-0.410 & -0.225 \\ (0.0986) & (0.130) \\ -0.888 & -0.196 \\ (0.189) & (0.227)\end{array}$

$-0.183$

(0.112)

$-0.557$

$-0.138$

(0.137)

Very confident

(0.189)

$(0.184)$

$-0.0481$

(0.226)

$-0.193$

(0.109)

$-0.275$

$-0.168$

$-0.0377$

$-0.100$

$0.275-0.0677$

0.201

0.0530

(0.207)

$(0.122)$

$-0.0770$

$-0.148$

(0.139)

Estimate of tuition and fees (natural log)

In-state tuition and fees in 2009 (natural log)

(0.0367)

(0.0351)

(0.0361)

0.211

(0.0349)

0.152

0.0428

$(0.208)$

0.0309
$(0.240)$

(0.191)

(0.186)

-0.644
$(0.248)$

(0.269)

(0.0346)

(0.0341)

0.112

(0.0359)

$-0.751$

0.0344

(0.185)

(0.281)

(0.0345)

0.449

(0.269)

Family Background

Family income (natural logarithm of dollars)

Parent/guardian years of education (most highly educated parent/guardian)

Parent/guardian years of education (other parent/guardian)

Parent/guardian occupational standing (highest SEI score)

Parent/guardian occupational standing (other SEI score)

$\begin{array}{cc}0.485 & 0.151 \\ (0.0845) & (0.103) \\ 0.114 & 0.0284 \\ (0.0282) & (0.0328) \\ 0.207 & 0.0774 \\ (0.0369) & (0.0431) \\ 0.00546 & 0.00690 \\ (0.00337) & (0.00382) \\ 0.00194 & -0.00111 \\ (0.00407) & (0.00499)\end{array}$

$\begin{array}{cc}0.346 & 0.117 \\ (0.0895) & (0.101) \\ 0.103 & 0.0288 \\ (0.0301) & (0.0328) \\ 0.168 & 0.0675 \\ (0.0411) & (0.0438) \\ 0.00402 & 0.00648 \\ (0.00351) & (0.00379) \\ 0.000927 & -0.00101 \\ (0.00428) & (0.00508)\end{array}$

Female

$\begin{array}{cc}0.504 & 0.373\end{array}$


Race (reference: White non-Hispanic)

Black of African-American

Hispanic

Asian or NHOPI

American Indian

$0.150 \quad-0.0391$

$(0.173) \quad(0.168)$

$-0.134 \quad 0.216$

$(0.162) \quad(0.167)$

$0.716 \quad 0.351$

$(0.228) \quad(0.277)$

$-0.347 \quad-0.524$

$(0.227) \quad(0.272)$

Urbanicity (reference: City)

Suburb

Town

Rural

$0.157 \quad-0.0352$

(0.142) (0.155)

$-0.0268 \quad 0.000214$

$(0.190) \quad(0.214)$
$-0.181 \quad-0.0204$

$-0.181 \quad-0.0204$

$(0.151) \quad(0.179)$

Region (reference: Northeast)

Midwest

South

West

Type of high school (reference: public) Catholic

Other private

$-0.216$

$(0.186)$

$-0.625$

$-0.231$

$(0.217)$

$(0.220$

$-0.949$

$-0.115$

$(0.239)$

(0.283)

$1.264 \quad 0.540$

(0.192) (0.224)

(0.208)

(0.331)
$0.781 \quad-0.0629$

0.645

$(0.194)$

Academic performance

Standardized math test (fall of ninth grade)

Self-reported math grade (eighth grade)

Self-reported science grade (eighth grade)
0.133

$(0.178)$

0.451

$(0.246)$

$-0.109$

(0.239)

0.178

(0.154)

$-0.812$

(0.240)

$-0.153$

(0.168)

$-0.207$

(0.193)

$-0.812$

$(0.240)$

$-1.0599$

(0.258)

1.345

(0.1202)

0.937

(0.249)

(0.223)

$-0.0153$

(0.349)

0.299

(0.166)

0.305

(0.284)

(0.268)

$-0.0301$

(0.153)

$-0.0293$

(0.209)

0.0105

(0.182)

$-0.216$

$(0.240)$

0.178

(0.274)

$\begin{array}{cccc}0.0623 & 0.0133 & 0.0545 & 0.0105 \\ (0.00611) & (0.00591) & (0.00613) & (0.00618) \\ 0.255 & -0.00608 & 0.290 & 0.0274 \\ (0.0781) & (0.0682) & (0.0746) & (0.0663) \\ 0.748 & 0.246 & 0.687 & 0.225\end{array}$




\begin{tabular}{|c|c|c|c|c|c|c|c|c|c|c|}
\hline & & & & & & & $(0.0753)$ & $(0.0777)$ & $(0.0783)$ & $(0.0727)$ \\
\hline Constant & 0.995 & 0.156 & -3.400 & -3.973 & -5.141 & -8.298 & -9.138 & -5.346 & -7.722 & -8.631 \\
\hline Model Chi-square & \multicolumn{2}{|c|}{35.35} & \multicolumn{2}{|c|}{102.3} & \multicolumn{2}{|c|}{748.9} & \multicolumn{2}{|c|}{556.3} & \multicolumn{2}{|c|}{1092} \\
\hline Degrees of Freedom & \multicolumn{2}{|c|}{4} & \multicolumn{2}{|c|}{8} & \multicolumn{2}{|c|}{44} & \multicolumn{2}{|c|}{14} & \multicolumn{2}{|c|}{50} \\
\hline
\end{tabular}

Source: See Table 1.

Notes: Results are weighted by the appropriate panel weight. $N=6,947$. Standard errors in parentheses. 


$\begin{array}{llll}\text { Model 2A } & \text { Model 3A } & \text { Model 4A } & \text { Model 5A }\end{array}$

Four-year Other Four-year Other Four-year Other Four-year Other Four-year Other

Confidence in estimate of tuition and fees (reference: not at all confident)

No measure of confidence

$\begin{array}{cccccccccc}-0.517 & -0.115 & -0.519 & -0.118 & -0.337 & -0.0557 & -0.138 & -0.263 & -0.0443 & -0.0147 \\ (0.125) & (0.158) & (0.125) & (0.159) & (0.133) & (0.164) & (0.129) & (0.159) & (0.140) & (0.166) \\ -0.372 & -0.214 & -0.373 & -0.214 & -0.139 & -0.115 & -0.163 & -0.160 & -0.00806 & -0.0821 \\ (0.0972) & (0.130) & (0.0973) & (0.130) & (0.111) & (0.135) & (0.108) & (0.130) & (0.121) & (0.137) \\ -0.910 & -0.210 & -0.907 & -0.206 & -0.523 & -0.00632 & -0.244 & -0.0588 & -0.0869 & 0.0850 \\ (0.183) & (0.227) & (0.182) & (0.226) & (0.179) & (0.233) & (0.205) & (0.241) & (0.205) & (0.246) \\ & & & & & & & & -0.250 \\ & & 0.296 & 0.395 & -0.514 & 0.573 & 0.280 & 0.405 & -.601 & -0.543 \\ & & (0.173) & (0.164) & (0.208) & (0.239) & (0.188) & (0.161) & (0.245) & (0.241)\end{array}$

Family Background

Family income (natural logarithm of dollars)

Parent/guardian years of education (most highly educated parent/guardian)

Parent/guardian years of education (other parent/guardian)

Parent/guardian occupational standing (highest SEI score)

Parent/guardian occupational standing (other SEI score)

$\begin{array}{cc}0.496 & 0.197 \\ (0.0766) & (0.0901) \\ 0.114 & 0.00848 \\ (0.0259) & (0.0300) \\ 0.211 & 0.0876 \\ (0.0407) & (0.0415) \\ 0.00199 & 0.00230 \\ (0.00303) & (0.00379) \\ 0.00412 & 0.000691 \\ (0.00331) & (0.00420)\end{array}$

$\begin{array}{cc}0.350 & 0.160 \\ (0.0807) & (0.0887) \\ 0.0992 & 0.0859 \\ (0.0263) & (0.0295) \\ 0.175 & 0.0784 \\ (0.0419) & (0.0416) \\ 0.000993 & 0.00234 \\ (0.00312) & (0.00373) \\ 0.00180 & 0.000153 \\ (0.00343) & (0.00429)\end{array}$

Female

$\begin{array}{cc}0.536 & 0.417 \\ (0.0820) & (0.0989)\end{array}$

$\begin{array}{cc}0.556 & 0.424 \\ (0.0889) & (0100)\end{array}$

Race (reference: White non-Hispanic) 
Black of African-American

Hispanic

Asian or NHOPI

American Indian

Urbanicity (reference: City)

Suburb

Town

Rural

Region (reference: Northeast) Midwest

South

West

Type of high school (reference: public) Catholic

Other private

\section{Academic performance}

Standardized math test (fall of ninth grade)

Self-reported math grade (eighth grade)

Self-reported science grade (eighth grade)
$-0.093 \quad-0.121$

$(0.137) \quad(0.172)$

$-0.0875 \quad 0.150$

$(0.151) \quad(0.135)$

$0.710 \quad 0.306$

$(0.188) \quad(0.258)$

$-0.367 \quad-0.406$

$(0.203)$

$(0.286)$

$0.165 \quad 0.0290$

$(0.117) \quad(0.133)$

$-0.198 \quad-0.0174$

$(0.179) \quad(0.227)$

$-0.118 \quad 0.00733$

$(0.125) \quad(0.149)$

$-0.108 \quad-0.0251$

$(0.140) \quad(0.172)$
-0.516

$\begin{array}{ll}-0.516 & 0.0609\end{array}$

(0.166) (0.193)

$-0.786 \quad 0.0473$

$(0.203) \quad(0.232)$

$1.251 \quad 0.622$

(0.166) (0.189)

$0.958 \quad 0.123$

(0.215) (0.292)
0.462

(0.156)

0.175

(0.173)

0.434

$(0.203)$

$-0.109$

(0.216)

0.198

$(0.130)$

$-0.210$

$(0.189)$

$-0.106$

(0.140)

$-0.122$

(0.153)

$-0.704$

(0.194)

$-0.919$

(0.228)

1.327

(0.185)

1.119

(0.253)

(0.196)

0.158

(0.312)

$\begin{array}{cccc}0.0701 & 0.0178 & 0.0596 & 0.0140 \\ (0.00538) & (0.00520) & (0.00531) & (0.00522) \\ 0.249 & -0.0187 & 0.263 & 0.00606 \\ (0.0655) & (0.0621) & (0.0600) & (0.0623) \\ 0.728 & 0.222 & 0.687 & 0.203\end{array}$




\section{Constant}

0.995

0.156

$-1.625$

$-3.341$

$-4.607$

$-8.849$

$-8.794$

$-4.984$

$-8.150$

888.9

54.29

48.82

8

44
737.8

14
$-9.471$

1199

50

Notes: Results are weighted by the appropriate panel weight. $N=8,939$. Standard errors in parentheses. 


\section{DESCRIPTION OF VARIABLE CONSTRUCTION}

\section{Socioeconomic Status (SES) Variables}

The HSLS dataset includes single-variable composite measures of SES for the base year and the first follow-up year, constructed for NCES by its contractors (see Ingels et al. 2011, 2014). We did not use either of these single-variable composite SES measures for our analysis and instead constructed five underlying measures: two parent/guardian education variables, two parent/guardian occupational standing variables, and one family income variable. In this section, we explain why and how we constructed these five variables.

General Strategy and Our Motivation. We know from past research that disaggregated measures of SES account for more variation in educational outcomes, and thus we assumed that adjustments using separate measures for the variables of parents' education, parents' occupational standing, and family income would be more appropriate than a single composite variable for SES that combines these separate indicators to form a single scale.

The contractors that conducted the HSLS, cognizant of this research, also produced composite variables for these underlying dimensions, which in the base year are named $x 1$ par1edu, x1par2edu, x1par1occ2, x1par2occ2, and x1famincome. In the first follow-up, similar variables were created as $x 2$ par1edu, $x 2$ par2edu, $x 2$ par1occ2, $x 2$ par2occ2, and $x 2$ famincome. These ten variables can be combined in pairs to create the desired five variables, although how best to do so requires a consideration of parent and student non-response patterns.

To develop our strategy to construct the five variables, we first considered the quality of the composite variables constructed by the contractors, assessing the consequences of the relatively low response rates for the base-year parent survey. In this assessment, we determined that

A. NCES, its contractors, and its technical review panel, decided not to include any questions on parents' education, parents' occupational standing, or family income on the base-year HSLS student questionnaire. For prior high school longitudinal surveys conducted by NCES, these items were typically included on the student survey instrument in order to compensate for likely missing data on the parent survey, assuming some non-response would occur.

B. The parent response rate in the base year was only 67.5 percent (Ingels et al. 2011:83; Ingels et al. 2014:45). When calculated for student participants, 23.4 percent of students did not have a parent or guardian who responded to the parent survey in the base year (Ingels et al. 2014:45). As noted above, because no student-level items on the dimensions of SES were included on the base-year student questionnaire, nearly one in four HSLS students had no valid 
information whatsoever for parent/guardian education and occupation, or for family income.

C. Because of these missing data problems for the dimensions of base-year SES, the contractors adopted a very aggressive imputation strategy in order to develop a single composite SES variable that NCES could release with the base-year data. Although it is not uncommon to rely on imputation when producing composite measures of this type, we were surprised by the list of imputation variables provided in the data documentation (see Ingels et al. 2011:J-12). Most crucially, these variables included the student's theta score, calculated from performance on the HSLS standardized math test administered in the base year. We do not believe that the typical researcher would expect a measure of SES to be based on any educational outcomes, even if such an imputation strategy could improve the expected accuracy of imputations and no matter how vigorously the contractors attempted to defend the imputation strategy (see Ingels et al. 2011:J11-J-13). Most researchers use measures of SES to adjust for confounding from family background when modeling educational outcomes, and thus most researchers would regard a composite measure imputed in this way to inject some over-control bias into a study of variation in individual-level measures of educational outcomes.

D. With recognition of these base-year measurement shortfalls, for the first followup survey NCES and its contractors attempted to collect additional data on SES in two ways. First, questions on parents' education and occupation were placed on the student questionnaire. Second, NCES administered a parent questionnaire to a random subsample of students, oversampling Hispanic students. With these two strategies, NCES was able to increase the percentage of respondents with some valid data on the dimensions of SES for the first followup.

With recognition of these complications, we decided to implement the following general strategy when constructing our five variables for parent/guardian education variables, parent/guardian occupational standing, and family income.

First, we decided to develop measures of the "big five" variables - two for parents'/guardians' education, two for parents'/guardians' occupational standing, and one for family income - by combining information in the ten base-year and first-follow-up composite variables: x1par1edu, x1par2edu, x1par1occ2, x1par2occ2, and x1famincome as well as $x 2$ par1edu, $x 2$ par2edu, $x 2$ par1occ $2, x 2$ par2occ 2 , and $x 2$ famincome. Although values for these composites include some imputed data, the base-year imputed values are generated by a well-designed hot deck imputation scheme among students whose parents answered at least some items on the parent questionnaire (see Ingels et al. 2011:162-65). The first follow-up composites are constructed similarly, but their imputation schemes take advantage of student responses to the 
items on their parents' educations and occupations. Altogether, the imputations in these ten composite variables, unlike the base-year, single-variable SES composite discussed above, were not based on any information on students' own educational outcomes. Nonetheless, because the imputation scheme was less aggressive, the base-year composite variables have many remaining missing values for students without any base-year parent/guardian data.

Second, we decided not to pursue a base-year set of measures, given the large amount of missing data in the base year for the SES components. Instead, we decided to combine the information in the relevant pair of variables in order use as much non-imputed data as possible. When valid (i.e., non-imputed) values were available for both the base year and first follow-up, we took the simple averages of the values (with the justification that this would minimize yearto-year fluctuation and measurement error, yielding, on average more valid measures of the stable core of SES).

Table A7 shows how each of the five variables were constructed for the 16,044 respondents analyzed in this article. For example, the family income variable is valid for 32.7 percent of respondents who had reported values in both the base year (BY) and the first followup (F1). We took the average of these two values. An additional 46.2 percent of respondents had valid BY family income and imputed F1 income. We averaged these two values, treating the imputations in the F1 composite as reasonable because they were based on a hot deck imputation scheme, using information from both students and parents. This also gave a parallel observation window across both years for the large majority of students, which matches our averaging of the BY and F1 valid values in the first column. As shown in the third column, 6.6 percent of respondents had valid F1 family income, but not BY family income. We kept these values and did not utilize the base-year imputations. And, finally, we accepted the F1 imputations of family income for 14.5 percent of respondents who did not have valid BY or F1 parent-reported values. These imputations were based on student responses to SES questions, in addition to other factors, and we judged these imputations to be high quality (see Ingels et al. 2014:146-52).

Table A7. Construction of the Dimensions of SES Based on Valid and Imputed Values for the Base Year and Follow-Up Composite Variables

\begin{tabular}{lccccc}
\hline \hline & $\begin{array}{c}\text { Average of } \\
\text { BY valid and } \\
\text { F1 valid }\end{array}$ & $\begin{array}{c}\text { Average of } \\
\text { BY valid and } \\
\text { F1 imputed }\end{array}$ & F1 valid & F1 imputed & $\begin{array}{c}\text { Our own } \\
\text { final-stage } \\
\text { imputation } \\
\text { for fill-in }\end{array}$ \\
\hline Family Income & & & & & \\
Parent 1 Education & $5,252(32.7)$ & $7,411(46.2)$ & $1,058(6.6)$ & $2,323(14.5)$ & $0(0)$ \\
Parent 2 Education & $5,689(35.5)$ & $7,517(46.9)$ & $1,009(6.3)$ & $1,829(11.4)$ & $0(0)$ \\
Parent 1 Occupation & $4,230(26.4)$ & $6,228(38.8)$ & $1,026(6.4)$ & $2,216(13.8)$ & $2,344(14.6)$ \\
Parent 2 Occupation & $5,379(33.5)$ & $7,343(45.8)$ & $1,054(6.6)$ & $2,013(12.6)$ & $255(1.6)$ \\
\hline Notes: The total $N$ for each row is the $N$ for the full sample of 16,044 & & & $2,358(14.7)$ & $2,591(16.2)$ \\
\hline
\end{tabular}

Finally, as shown in the last column of Table A7, we used our own procedure to impute the remaining missing cases for three of the five variables, which in most cases were for 
hypothetical "second parents" who we assume were not in fact present in the students' households. We used single-value, best-subset, regression imputation with the other available dimensions of SES, as well as additional student and school characteristics (e.g., race of student, region, urbanicity, type of school, cost-adjusted per-pupil expenditures on instructional salaries, and racial composition of school). Our imputations in this final step were enacted to fill in the missing data for "second parents" in order to enable an adjustment scheme that would utilize all five variables for all respondents, including those from single parent/guardian households.

Additional Detail for Parent/Guardian Educational Standing. As described above, we used the combined information in the four composite variables $x 1$ par1edu, $x 1$ par2edu, $x 2$ par1edu, and $x 2$ par2edu. These HSLS variables are categorical variables that indicate the highest level of education of "parent 1 " and "parent 2. ." We recoded these categories as

$\begin{array}{ll}\text { Category } & \frac{\text { Assigned Years }}{10 \text { years }} \\ \text { Less than high school } & 12 \text { years } \\ \text { High school diploma or GED } & 14 \text { years } \\ \text { Associate's degree } & 16 \text { years } \\ \text { Bachelor's degree } & 18 \text { years } \\ \text { Master's degree } & 18 \text { years } \\ \text { Educational Specialist diploma } & 20 \text { years }\end{array}$

We coded these categories as years based on the standards in our reading of the literature, although we do not know if our reading of the literature matches those of others.

Additional Detail for Parent/Guardian Occupational Standing. As described above, we used the combined information in the four composite variables $x 1$ par1occ2, x1par2occ2, $x 2$ par1occ 2 , and $x 2$ par2occ 2 . These variables are coded according to the 2010 Standard Occupational Classification (SOC) Major Groups (see below for the 23 groups), based on a firststage categorization of the job title and job activities elicited in response to questions with respondent-appropriate syntax variations:

[What is/In [your/her/his] most recent job, what was] [your/her/his] job title? If [you/she/he] [have/has/had] more than one job, describe the one at which [you/she/he] [work/works/worked] the most hours. What [do/does/did] [you/she/he] actually do in that job? That is, what [are/were] [your/her/his] main activities or duties?

The 23 groups used for $x 1$ par1occ2, x1par2occ2, x2par1occ2, and $x 2$ par2occ2 are

$\underline{\text { SOC Major (Two-Digit) Occupational Group }}$

11 Management Occupations

13 Business and Financial Operations Occupations

15 Computer and Mathematical Occupations

17 Architecture and Engineering Occupations

19 Life, Physical, and Social Science Occupations

21 Community and Social Services Occupations
Contractor

52.0

48.0

58.4

59.7

61.2

50.4
GSS 2012

68.2

70.0

78.8

78.8

79.5

61.5 


$\begin{array}{lll}23 \text { Legal Occupations } & 63.3 & 79.9 \\ \text { 25 Education, Training and Library Occupations } & 62.2 & 73.4 \\ \text { 27 Arts, Design, Entertainment, Sports, and Media Occupations } & 50.2 & 64.3 \\ \text { 29 Healthcare Practitioners and Technical Occupations } & 64.2 & 75.4 \\ \text { 31 Healthcare Support Occupations } & 41.4 & 27.2 \\ \text { 33 Protective Service Occupations } & 50.7 & 55.8 \\ \text { 35 Food Preparation and Serving Related Occupations } & 27.1 & 18.9 \\ \text { 37 Building and Grounds Cleaning and Maintenance Occupations } & 30.2 & 20.3 \\ \text { 39 Personal Care and Service Occupations } & 33.2 & 27.3 \\ \text { 41 Sales and Related Occupations } & 34.0 & 48.5 \\ \text { 43 Office and Administrative Support Occupations } & 37.7 & 38.6 \\ \text { 45 Farming, Fishing, and Forestry Occupations } & 31.7 & 18.0 \\ \text { 47 Construction and Extraction Occupations } & 36.4 & 33.6 \\ \text { 49 Installation, Maintenance, and Repair } & 40.1 & 40.4 \\ \text { 51 Production Occupations } & 35.3 & 33.3 \\ \text { 53 Transportation and Material Moving Occupations } & 36.5 & 30.8 \\ \text { 55 Military Specific Occupations } & 56.5 & 55.6\end{array}$

For the construction of the single-value SES composite variables (that we did not use, as explained above), the categorization of the 23 major groups was converted to an interval scale. The HSLS documentation does not describe the scaling of these groups, although the text of the documentation implies that a traditional SEI scale was used. The contractors to NCES shared with us the values they used, which they indicated were based on their own analysis of SEI scores from the 1989 General Social Survey study of occupational prestige (often referred to as the Nakao-Treas 1989 GSS coding). The specific values provided by the contractors are listed above in the "contractors" column.

Although the values used by the contractors appeared reasonable to us, we do not understand how they were constructed. There is no available mapping from the 1980 census occupation codes used for the 1989 GSS study to the 2010 SOC codes used for occupations reported for the HSLS. In fact, the census bureau's own work on conversion rates of occupation categories from the two schemes revealed, in a comparison of 1990 census codes to 2000 SOC codes, very substantial variation in the categorization of detailed job titles that could not be reconciled at the occupation level.

Fortunately, not long after the HSLS was fielded, the GSS adopted 2010 census occupation codes for its 2012 survey (and subsequent surveys). The 2010 occupation codes can be mapped to the 2010 SOC used for the HSLS. In addition, the GSS replicated the 1989 occupational prestige study using its 2012 panel sample, generating a new set of SEI scores (see Smith and Son 2014, GSS Methodological Report 122 and Hout, Smith, and Marsden 2016, GSS Methodological Report 124).

Drawing on this new work, we created our own SEI values for the 23 SOC major groups, as shown in the final column above, labeled "GSS 2012." We used the SEI values from the file provided with Hout, Smith, and Marsden (2016, GSS Methodological Report 124). These SEI values are near equal averages of scales of years of education and personal earnings of 
occupational incumbents for respondents to the American Community Survey (ACS), with the near equal weighting justified by the prestige ratings from GSS respondents' assessments of hundreds of job titles. The values exist for nearly 500 occupations embedded in the 23 SOC major groups listed above. We matched these values to individuals with occupations in our own analysis of the public-use, micro-sample data of the ACS, for the years 2010 through 2014. We calculated SOC major group means of the SEI values for occupations embedded within them, based on the occupation distribution of ACS respondents between the ages of 32 and 52 (which is a reasonable range for the parents/guardians of HSLS ninth graders in 2009). These are the values in the final column above. They differ from those used by the contractors, but not by much other than a shift in scale. By our calculations, the two scales have a correlation of 0.92 for the HSLS sample of parents.

Additional Detail for Family Income. As described above, we used the combined information in the two composite variables $x 1$ famincome and $x 2$ famincome. These HSLS variables are categorical variables that indicate the sample member's family income from all sources in 2008 and 2011, as reported on the parent questionnaire, or as imputed with the hot deck procedure described above. The item wording is:

We understand that you may not be able to provide an exact number for your family's income. However, it would be extremely helpful if you would indicate which of the following ranges best estimates your total household income from all sources prior to taxes and deductions in calendar year 2008/2011. Please include all income such as income from work, investments and alimony.

The response categories were:

$$
\begin{aligned}
& \$ 15,000 \text { or less } \\
& \$ 15,001-\$ 35,000 \\
& \$ 35,001-\$ 55,000 \\
& \$ 55,001-\$ 75,000 \\
& \$ 75,001-\$ 95,000 \\
& \$ 95,001-\$ 115,000 \\
& \$ 115,001-\$ 135,000 \\
& \$ 135,001-\$ 155,000 \\
& \$ 155,001-\$ 175,000 \\
& \$ 175,001-\$ 195,000 \\
& \$ 195,001-\$ 215,000 \\
& \$ 215,001-\$ 235,000 \\
& \text { More than } \$ 235,000
\end{aligned}
$$

We recoded the values to the midpoints of each response range, while setting the " 15,000 or less" category to 15,000 and the "more than 235,000 " category to 235,000 . We then took the 
natural logarithm of these values, which we regard as the standard scaling of family income in the education literature. 


\section{REFERENCES}

Hout, Michael, Tom W. Smith, and Peter V. Marsden. 2016. “Prestige and Socioeconomic Scores for the 2010 Census Codes." GSS Methodological Report No. 124, National Opinion Research Center, Chicago, Illinois.

Ingels, Steven J., Daniel J. Pratt, Deborah R. Herget, Laura J. Burns, Jill A. Dever, Randolph Ottem et al. 2011. "High School Longitudinal Study of 2009 (HSLS:09). Base-Year Data File Documentation (NCES 2011-328)." U.S. Department of Education, National Center for Education Statistics, Washington, DC.

Ingels, Steven J., Daniel J. Pratt, Deborah R. Herget, Jill A. Dever, Laura Burns Fritch, Randolph Ottem et al. 2014. "High School Longitudinal Study of 2009 (HSLS:09) Base Year to First Follow-up Data File Documentation (NCES 2014-361)." U.S. Department of Education, National Center for Education Statistics, Washington, DC.

Smith, Tom W. and Jaesok Son. 2014. "Measuring Occupational Prestige in the 2012 General Social Survey." GSS Methodological Report No. 122, National Opinion Research Center, Chicago, Illinois. 


\section{Appendix B}

for

\section{Overconfidence and Uncertainty: High School Students' Beliefs About College Tuition and Their Subsequent College-Entry Rates}

\section{An Explanation of Skip Patterns with an Annotated Excerpt of the HSLS 2009 Student Questionnaire}

In this appendix, we have reproduced below an excerpt of the pdf file released by the National Center for Education Statistics that includes all items on the 2009 base-year HSLS questionnaire administered to ninth graders. All text printed in black typeface is present in exact form in the pdf of the questionnaire items. The additional text in red typeface was added by us to explain our excerpting, number the questions we include below, and then explain the skip patterns built into the instrument design.

As explained by the red typeface below, two routes exist through the questionnaire after question G5 filters respondents into those who indicate whether they expect that they will or will not attempt to earn a bachelor's degree:

1. One group of students, which is comparatively small and not the focus of our study, claims to have "gotten information" by the fall of ninth grade about the cost of tuition and mandatory fees at a specific private, public in-state, or public out-of-state four-year college (presumably for an institution that they will consider attending). This group is composed of those who offer answers to questions G6, G7, and G8. At that point, this group alone receives questions G9 through G14 on the expected tuition and fees at the specific institution for which they have gotten information. This group never receives our focal questions G15 and G17.

2. The second group, which is much larger and is the focus of our study, is filtered out of the first group progressively in questions G5, G6, G7, and G8 (as individuals who have not gotten specific information about the costs of tuition and mandatory fees at a specific 
private, public in-state, or public out-of-state four-year college). ${ }^{1}$ This group instead skips directly to our first focal question G15, "What is your best estimate of the cost of one year's tuition and mandatory fees at a public 4-year college in your state?" If members of this group offer a specific numerical estimate for tuition and mandatory fees in response to question G15, they also receive questions G16 and G17.

All groups are reunited at question G18, and they all proceed through to the final question G20 in that section of the questionnaire.

\footnotetext{
${ }^{1}$ We also trim out of this second group in our analysis all ninth graders who do not indicate in G5 that they planned to obtain some type postsecondary training during their first year after high school graduation, defined as responses A through D below for G5.
} 
U.S. Department of Education

National Center for Education Statistics
High School Longitudinal Study of 2009

OMB No: 1850-0852

${ }^{*}$ Questions marked with an asterisk $\left({ }^{*}\right)$ were not asked of all respondents.

\title{
SECTION A: Student Background
}

[ 10 Questions Omitted ]

\section{SECTION B: Previous School Experiences}

[ 9 Questions Omitted ]

SECTION C: Math Experiences

[ 9 Questions Omitted ]

SECTION D: Science Experiences

[ 9 Questions Omitted ]

SECTION E: Home and School

[16 Questions Omitted ]

\section{SECTION F: Plans for Postsecondary Education}

\author{
[ 10 Questions Omitted ]
}

Note: Section F has a misleading label. Most questions in this section are about plans for high school education, although they are asked with question wording that points toward the future, such as "What are the reasons you plan to take more math courses during high school?"

\section{SECTION G: Life After High School}

Now we are going to ask you a few questions about your future life after high school. We understand that you may not have thought a lot about some of these questions or you may not have all of the information right now. If you are unsure about how to answer a question, please make your best guess. Your thoughts are very important to us.

G1. As things stand now, how far in school do you think you will get?
A. Less than high school
B. High school diploma or GED
C. Start but not complete an Associate's degree
D. Complete an Associate's degree
E. Start but not complete a Bachelor's degree
F. Complete a Bachelor's degree
G. Start but not complete a Master's degree 
H. Complete a Master's degree

I. Start but not complete a Ph.D., M.D., law degree, or other high level professional degree

J. Complete a Ph.D., M.D., law degree, or other high level professional degree

K. Don't know

IF respondent answers E, F, G, H, I, or J, then CONTINUE to G2

IF respondent answers A, B, C, D, K, or did not respond, then SKIP to G3.

* G2. How sure are you that you will go on to college to pursue a Bachelor's degree after you leave high school?

Very sure you'll go

You'll probably go

You probably won't go

Very sure you won't go

Respondents received this question if they:

Indicated that they expected to attempt to earn at least a bachelor's degree (indicated by responding $\mathrm{E}, \mathrm{F}, \mathrm{G}, \mathrm{H}$, I, or J) to question G1

G3. Whatever your plans, do you think you have the ability to complete a Bachelor's degree?

Definitely

Probably

Probably not

Definitely not

G4. Would you be disappointed if you did not graduate from college with a Bachelor's degree by the time you are 30 years old?

Yes

No

G5. What do you plan to do during your first year after high school?

(check all that apply.)

A. Enroll in an Associate's degree program in a two-year community college or technical institute

B. Enroll in a Bachelor's degree program in a college or university

C. Obtain a license or certificate in a career field

D. Attend a registered apprenticeship program

E. Join the armed services

F. Get a job

G. Start a family

H. Travel

I. Do volunteer or missionary work 
J. Not sure what you want to do

IF respondent checks B, then CONTINUE to G6

IF respondent does not check B, then SKIP to G15.

* G6. Are you more likely to attend a public or private 4-year college, or have you not thought about this yet?
A. Public
B. Private
C. Haven't thought about this

IF respondent answers $\mathrm{A}$, then CONTINUE to G7

IF respondent answers $\mathrm{B}$, then SKIP to G8

IF respondent answers $C$ or does not respond, then SKIP to G15

Respondents received this question if they:

Answered B "Enroll in a Bachelor's degree program in a college or university" to question G5

* G7. Are you more likely to attend an in-state or out of state 4-year college, or have you not thought about it yet?
A. In-state
B. Out of state
C. Haven't thought about this

IF respondent answers A or B, then CONTINUE to G8

IF respondent answers $\mathrm{C}$ or does not respond, then SKIP to G15

Respondents received this question if they:

Answered B "Enroll in a Bachelor's degree program in a college or university" to question G5

AND

Answered A "Public" to question G6

* G8. Have you gotten information about the cost of tuition and mandatory fees at a specific [instate public/out-of-state public/private] college?
A. Yes
B. No

The wording in the brackets of G8 is set by responses to G6 and G7.

IF respondent answers A, then SKIP to G9, G11, or G13 depending on responses to G6 and G7 IF respondent answers B or does not respond, then SKIP to G15 
Respondents received this question if they:

Answered B "Enroll in a Bachelor's degree program in a college or university" to question G5

AND

Answered A "Public" to question G6

AND

Answered A "In-State" or B "Out of state" to question G7

OR

Answered B "Enroll in a Bachelor's degree program in a college or university" to question G5

AND

Answered B "Private" to question G6

* G9. What is the cost of one year's tuition and mandatory fees at that public 4-year college in your state?

Include the cost of courses and required fees such as student activity fees and student health fees. Do not include optional expenses such as room and board.

IF respondent answers with a specific numerical estimate, then CONTINUE to G10

IF respondent does not answer with a specific numerical estimate, then SKIP to G18

Respondents received this question if they:

Answered B "Enroll in a Bachelor's degree program in a college or university" to question G5

AND

Answered A "Public" to question G6

AND

Answered A "In-state" to question G7

AND

Answered A "Yes" to question G8

* G10. Is that tuition and mandatory fees only, or does that also include other fees such as room and board?

Tuition and mandatory fees only

Tuition, mandatory fees, and other fees

Regardless of answer, SKIP to G18.

Respondents received this question if they: 
Answered B "Enroll in a Bachelor's degree program in a college or university" to question G5

AND

Answered A "Public" to question G6

AND

Answered A "In-state" to question G7

AND

Answered A "Yes" to question G8

AND

Answered G9 with a specific numerical estimate

* G11. What is the cost of one year's tuition and mandatory fees at that private 4-year college? Include the cost of courses and required fees such as student activity fees and student health fees. Do not include optional expenses such as room and board.

IF respondent answers with a specific numerical estimate, then CONTINUE to G12

IF respondent does not answer with a specific numerical estimate, then SKIP to G18.

Respondents received this question if they:

Answered B "Enroll in a Bachelor's degree program in a college or university" to question G5

AND

Answered B "Private" to question G6

AND

Answered A "Yes" to question G8

* G12. Is that tuition and mandatory fees only, or does that also include other fees such as room and board?

Tuition and mandatory fees only

Tuition, mandatory fees, and other fees

Regardless of answer, SKIP to G18.

Respondents received this question if they:

Answered B "Enroll in a Bachelor's degree program in a college or university" to

AND question G5

Answered B “Private” to question G6

AND

Answered A "Yes" to question G8

AND

Answered G11 with a specific numerical estimate 
* G13. What is the cost of one year's tuition and mandatory fees at that out-of-state public 4-year college?

Include the cost of courses and required fees such as student activity fees and student health fees. Do not include optional expenses such as room and board.

IF respondent answers with a specific numerical estimate, then CONTINUE to G14

IF respondent does not answer with a specific numerical estimate, then SKIP to G18.

Respondents received this question if they:

Answered B "Enroll in a Bachelor's degree program in a college or university" to question G5

AND

Answered A "Public" to question G6

AND

Answered B "Out of state" to question G7

AND

Answered A "Yes" to question G8

* G14. Is that tuition and mandatory fees only, or does that also include other fees such as room and board?

Tuition and mandatory fees only

Tuition, mandatory fees, and other fees

Regardless of answer, SKIP to G18.

Respondents received this question if they:

Answered B "Enroll in a Bachelor's degree program in a college or university" to question G5

AND

Answered A "Public" to question G6

AND

Answered B "Out of state" to question G7

AND

Answered A "Yes" to question G8

AND

Answered G13 with a specific numerical estimate

* G15. What is your best estimate of the cost of one year's tuition and mandatory fees at a public 4-year college in your state?

Include the cost of courses and required fees such as student activity fees and student health fees. Do not include optional expenses such as room and board.

IF respondent answers with a specific numerical estimate, then CONTINUE to G16 
IF respondent does not answer with a specific numerical estimate, then SKIP to G18.

Respondents received this question if they:

Answered B "Enroll in a Bachelor's degree program in a college or university" to question G5

AND

Answered C “Haven't though about this" or did not respond to question G6

OR

Answered B "Enroll in a Bachelor's degree program in a college or university" to question G5

AND

Answered A "Public" to question G6

AND

Answered C “Haven't though about this" or did not respond to question G7

OR

Answered B "Enroll in a Bachelor's degree program in a college or university" to question G5

AND

Answered A "Public" to question G6

AND

Answered A "In-State" or B "Out of state" to question G7

AND

Answered B "No" to question G8 because did not receive specific information

OR

Answered B "Enroll in a Bachelor's degree program in a college or university" to question G5

AND

Answered B “Private" to question G6

AND

Answered B "No" to question G8 because did not receive specific information

* G16. Is that tuition and mandatory fees only, or does that also include other fees such as room and board?

Tuition and mandatory fees only

Tuition, mandatory fees, and other fees

Regardless of answer, CONTINUE to G17. 
Respondents received this question if they:

Answered B "Enroll in a Bachelor's degree program in a college or university" to question G5

AND

Answered C "Haven't though about this" to question G6

AND

Answered with a specific numerical estimate for G15

OR

Answered B "Enroll in a Bachelor's degree program in a college or university" to question G5

AND

Answered A “Public" to question G6

AND

Answered C "Haven't though about this" to question G7

AND

Answered with a specific numerical estimate for G15

OR

Answered B "Enroll in a Bachelor's degree program in a college or university" to question G5

AND

Answered A "Public" to question G6

AND

Answered A "In-State" or B "Out of state" to question G7

AND

Answered B "No" to question G8 because did not receive specific information AND

Answered with a specific numerical estimate for G15

OR

Answered B "Enroll in a Bachelor's degree program in a college or university" to question G5

AND

Answered B "Private" to question G6

AND

Answered B "No" to question G8 because did not receive specific information AND

Answered with a specific numerical estimate for G15 
* G17. How confident are you in the accuracy of your estimate of the cost of one year's tuition and mandatory fees at a public 4-year college in your state? Are you...

very confident

somewhat confident or

not at all confident?

Regardless of answer, CONTINUE to G18.

Respondents received this question if they:

Answered B "Enroll in a Bachelor's degree program in a college or university" to question G5

AND

Answered C "Haven't though about this" to question G6

AND

Answered with a specific numerical estimate for G15

OR

Answered B "Enroll in a Bachelor's degree program in a college or university" to question G5

AND

Answered A "Public" to question G6

AND

Answered C "Haven't though about this" to question G7

AND

Answered with a specific numerical estimate for G15

OR

Answered B "Enroll in a Bachelor's degree program in a college or university" to question G5

AND

Answered A "Public" to question G6

AND

Answered A "In-State” or B “Out of state" to question G7

AND

Answered B "No" to question G8 because did not receive specific information AND

Answered with a specific numerical estimate for G15

OR 
Answered B "Enroll in a Bachelor's degree program in a college or university" to question G5

AND

Answered B "Private" to question G6

AND

Answered B "No" to question G8 because did not receive specific information

AND

Answered with a specific numerical estimate for G15

G18. As things stand now, what is the job or occupation that you expect or plan to have at age $30 ?$
A. You don't know
B. No
C. Yes

IF respondent answers B or C, then CONTINUE to G19

IF respondent answers A or did not respond, then SKIP to G20

* G19. How much have you thought about this choice? Have you thought about it... not at all

a little somewhat or

a lot?

Regardless of answer, CONTINUE to G20

Respondents received this question if they:

Answered B "No" or C "Yes" to question G18.

G20. When you talk about your plans for the future, would you say you talk...

mostly to your parents

more to your parents than your friends

to your parents and your friends about the same

more to your friends than your parents

mostly to your friends or

you don't talk to your parents or to your friends about your plans for the future? 